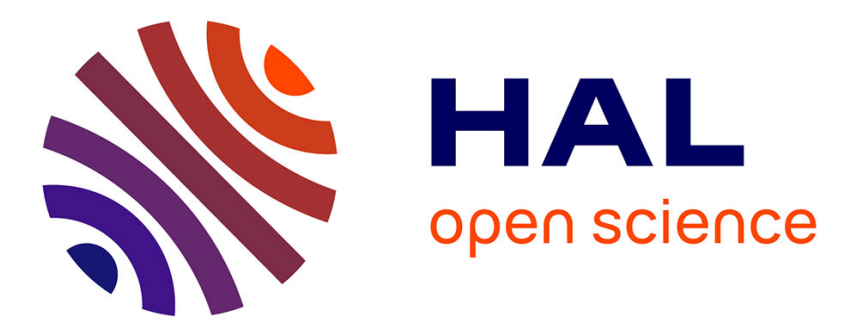

\title{
A Method for Fault Detection and Isolation based on the Processing of Multiple Diagnostic Indices: Application to Inverter Faults in AC Drives
}

\author{
Fabien Meinguet, Paul Sandulescu, Xavier Kestelyn, Eric Semail
}

\section{- To cite this version:}

Fabien Meinguet, Paul Sandulescu, Xavier Kestelyn, Eric Semail. A Method for Fault Detection and Isolation based on the Processing of Multiple Diagnostic Indices: Application to Inverter Faults in AC Drives. IEEE Transactions on Vehicular Technology, 2013, pp.15. 10.1109/TVT.2012.2234157 . hal-00783424

\author{
HAL Id: hal-00783424 \\ https://hal.science/hal-00783424
}

Submitted on 1 Feb 2013

HAL is a multi-disciplinary open access archive for the deposit and dissemination of scientific research documents, whether they are published or not. The documents may come from teaching and research institutions in France or abroad, or from public or private research centers.
L'archive ouverte pluridisciplinaire $\mathbf{H A L}$, est destinée au dépôt et à la diffusion de documents scientifiques de niveau recherche, publiés ou non, émanant des établissements d'enseignement et de recherche français ou étrangers, des laboratoires publics ou privés. 


\title{
A Method for Fault Detection and Isolation based on the Processing of Multiple Diagnostic Indices: Application to Inverter Faults in AC Drives
}

\author{
Fabien Meinguet, Paul Sandulescu, Xavier Kestelyn, and Eric Semail
}

\begin{abstract}
A general method for fault detection and isolation is proposed and applied to inverter faults in drives of electric vehicles. This method is based on a change-detection algorithm, which allows multiple fault indices to be combined for retrieving the most likely state of the drive. The drive topology under study is a six-leg inverter associated with a three-phase open-end winding machine. Due to the inherent fault-tolerant topology, the conventional fault indices are no longer effective. Therefore, an analysis of simulations in faulty conditions leads to the derivation of suitable fault indices. These are based on the envelope of the phase currents as well as their instantaneous frequency. Specific operating conditions related to the electric vehicle environment are taken into account, such as the flux-weakening region and energy recovery. In these modes of operation, fault detection and isolation can be affected by uncontrolled currents circulating through the free-wheeling diodes. Finally, the performances of the fault detection and isolation scheme are evaluated under steady state and non-stationary conditions through simulations and experimental results.
\end{abstract}

Index Terms-AC machines, Change detection algorithms, Condition monitoring, Drives, Electric vehicles, Fault detection, Fault diagnosis, Inverters, Permanent magnet machines, Phase locked loops.

\section{NOMENCLATURE}

$\begin{array}{ll}\Delta t_{F D I} & \text { Detection delay. } \\ \epsilon_{j} & \text { Magnitude of fault } j . \\ \kappa_{l, j} & \text { Distance between fault } l \text { and fault } j . \\ {\left[\mu_{j}\right]} & \text { Vector of the mean values of the fault indices } \\ & \text { upon the occurrence of fault } j . \\ \zeta_{P L L} & \text { PLL damping factor. } \\ {[\Sigma]} & \text { Variance matrix of the fault indices. } \\ {[I]} & \text { Incidence matrix. } \\ \omega_{e} & \text { Electrical pulsation. } \\ \omega_{m} & \text { Mechanical pulsation. } \\ \omega_{P L L} & \text { PLL bandwidth. } \\ \omega_{x} & \text { Instantaneous pulsation of phase- } x \text { current. } \\ g_{j}^{*} & \text { CUSUM function associated with fault } j . \\ h_{F D I} & \text { Isolation threshold. }\end{array}$

Copyright (c) 2012 IEEE. Personal use of this material is permitted. However, permission to use this material for any other purposes must be obtained from the IEEE by sending a request to pubs-permissions@ieee.org

Manuscript received July 18, 2012; revised October 30, 2012.

This work was supported by the French F.U.I. and Valeo in the frame of the SOFRACI project.

Authors are with Arts et Métiers ParisTech, L2EP, Lille, France. Corresponding author is prof. Eric Semail. E-mail: eric.semail@ensam.eu.

$\begin{array}{ll}H_{0} & \text { Healthy state. } \\ I_{a b c} & \text { Phase currents. } \\ I_{0 d q} & \text { Phase currents expressed in the synchronous } \\ & \text { reference frame. } \\ L_{d q} & d \text { - and } q \text {-axis inductances. } \\ L_{0} & \text { Zero-sequence inductance. } \\ M_{x} & \text { Envelope of the phase- } x \text { current. } \\ n_{R} & \text { Number of fault indices. } \\ n_{f} & \text { Number of faults. } \\ N_{p p} & \text { Number of pole pairs. } \\ {[r(k)]} & \text { Vector representing the values of the fault } \\ R_{S} & \text { indices at time } k . \\ R_{M_{x y}} & \text { Stator resistance. } \\ R_{\omega_{x}} & \text { Fault index based on the envelopes } M_{x} \text { and } M_{y} . \\ & \text { Fault index based on the instantaneous } \\ S_{j, l} & \text { frequency } \omega_{x} \\ S_{X Y} & \text { Log-likelihood ratio between states } j \text { and } l . \\ & \text { Switch associated with phase } x \text { and located at } \\ T_{S} & \text { the position } y \text {. } \\ V_{D C} & \text { Sampling period. } \\ \mathrm{BO} & \text { DC-link voltage. } \\ \mathrm{CUSUM} & \text { Open-circuit fault occurring on phase } b . \\ \mathrm{EV} & \text { Cumulative sum. } \\ \mathrm{FDI} & \text { Electric vehicle. } \\ \mathrm{LLR} & \text { Fault detection and isolation. } \\ \mathrm{PI} & \text { Log-likelihood ratio. } \\ \mathrm{SRF} & \text { Proportional integral. } \\ \mathrm{SWAO} & \text { Phase-Locked Loop. } \\ & \text { Quadrature-signal generator. } \\ & \text { Synchronous reference frame. } \\ & \end{array}$

\section{INTRODUCTION}

R ELIABILITY of drives has been studied for decades [1]. This has been recognized as a key feature in transportation systems in which failures can have dramatic effects.

Inverter parts are often pointed out as the weakest components of drives. Statistics generally show that the failure rates of power semiconductors, gate drives and capacitors are higher than those of electric machines [2], [3], even if controller failure rates are significant as well [3], [4].

Condition monitoring is a way to avoid unexpected down times as this allows the fault detection at an incipient stage, i.e. before the fault develops into a failure. Condition monitoring applied to electric machines is nowadays a mature 
technology which has received a large acceptance in industry. Techniques based on the motor current or voltage analysis have been widely investigated [5]-[8]. On the other hand, inverter failures remain difficult to predict. Although there are recent developments in this field exposed in [9], improvements are still required to allow a large-scale implementation.

As inverter faults can hardly be predicted, fault tolerance has been the only way to prevent a shutdown of the drive in the occurrence of a failure. Fault tolerance capability has been investigated for electric machines [10]-[13] and for inverters. In [14], several fault-tolerant inverter topologies associated with a three-phase machine are compared, whereas multiphase drives are addressed in [15], [16].

Initially, fault tolerance has been introduced for safetycritical systems. Examples may be found for aerospace actuators [17], [18], steer-by-wire and brake-by-wire systems [19] or in-wheel motors [20], [21]. Recently, further investigations on a fault-tolerant topology have shown how to integrate a cheap and fast on-board charger [22], [23], making fault tolerance cost effective for electric vehicles (EVs) as well. This topology is composed of a six-leg inverter associated with a three-phase permanent-magnet synchronous machine (PMSM). No additional component is required for the charging functionality, what is an advantage over the solution proposed in [24] for example, where an additional clutch is required.

There are several ways to implement a fault-tolerant control (FTC). Relying on the inherent fault tolerance is the simplest way to accommodate a fault. With this scheme, the post-fault performances are estimated to be satisfactory without any change of the control laws. On the other hand, a control reconfiguration allows a modification of the control laws to operate the drive as well as possible in its current condition. In the latter case, a robust fault diagnosis is paramount.

In [25], a technique based on two observers allows FTC to be implemented for mechanical sensor failures. A maximumlikelihood voting algorithm is used to determine which is the most appropriate input for the control loops.

Current-sensor faults are addressed in [26]-[29]. In [26], an offline test allows determining the faulty sensors and FTC is achieved by replacing the measurement by software estimation. In [27], the fault detection and isolation (FDI) is performed during a short period of open-loop operation. In [28] a signal-based technique and the generalized observer scheme are proposed for the fault isolation, again with an open-loop controller. In [29], hardware redundancy is used to isolate the fault in closed-loop operation and at zero speed.

In case of sensor faults, it is also possible to adapt the control strategy in function of the available sensors, as presented in [30].

Regarding inverter faults, the most common method for fault detection consists in detecting the desaturation of the transistors by monitoring the collector-emitter voltage. This feature is available in many drivers and is often considered as the short-circuit fault detection for power electronics devices. However, this does not protect the system against other events such as driver failures or gate-command-signal failures. Consequently, research has been dedicated to the detection and isolation of open-phase faults or single-switch open- circuit faults [31]-[37]. In [31], the authors investigate two methods: the analysis of the current-vector trajectory and of the derivative of the current-vector phase, both methods being based on the $\alpha \beta$ currents. In [32], a simulation model of the faulty drive is used to train an artificial neural network. In [33], the detection is based on the pattern of the $\alpha \beta$ currents, which is analyzed by a fuzzy technique allowing to isolate the fault and to assess its severity. In [34], the authors focus the analysis on the normalized dc components of the phase currents. By associating additional diagnostic variables such as the number of phase-current samples close to zero and indices of unbalance, a detection of multiple faults is achieved. In [35] a similar idea based on the normalized currents' average absolute values is proposed. In [36], the derivative of the current-vector phase is combined with an analysis of the polarity of the phase currents to detect and isolate multiple faults. In [37], a model-based technique is proposed. The fault is modeled as an additive fault acting on the control variables. The isolation is performed by analyzing residuals obtained through observers in the $\alpha \beta$ frame.

It has to be noticed that all the aforementioned methods have been proposed for three-leg inverters.

In case a fault-tolerant inverter is used, the drive accommodates the fault and the $\alpha \beta$ components are not much affected, making ineffective all the methods relying on these components. However, methods based on the normalized DC component such as [34] and [35] can still be suitable.

Another observation is that none of the previous works has analyzed the detection of faults in the flux-weakening region or in generator mode. These modes of operation are very important for EVs as the electric machines are designed for a large constant-power operation and for energy recovery [38]. In the flux-weakening region, the electromotive force is larger than the DC-link voltage. Consequently, an uncontrolled current passing through the free-wheeling diodes can be observed in case of fault. This uncontrolled current affects the performance of the FDI scheme.

In this paper, a method for fault detection and isolation of open-phase and single-switch open-circuit faults is investigated for a topology composed of a six-leg inverter and a three-phase machine. The objectives are to locate the faulty phase and to distinguish the open-phase fault from the singleswitch open-circuit fault. This minimum information can be used to initiate a control reconfiguration, which can adapt the current references to obtain a control with zero torque ripple as proposed in [39]-[42].

The block diagram of the proposed FDI scheme is presented in Fig. 1. Based on the available measurements, i.e. the phase currents and the mechanical speed, a pre-processing is firstly applied. This allows the magnitude of each phase current and their instantaneous frequency to be extracted through signal processing techniques proposed in [43] and [44], i.e. a quadrature-signal generator (QSG) and a phase-locked loop (PLL) respectively.

Next, two sets of fault indices (FI) are generated. The first set is based on the magnitude of the phase currents and the second is based on the instantaneous-frequency estimation of each phase current. The advantages of the proposed indices are a reduced number of operations and no data storage. 


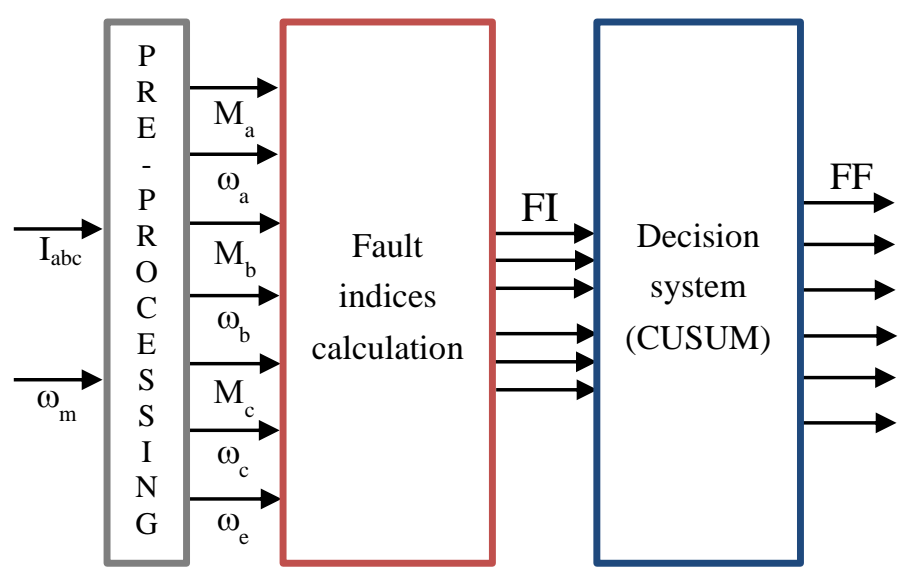

Fig. 1. Block diagram of the FDI scheme.

Finally, the decision system is implemented with a changedetection algorithm referred to as the cumulative sum (CUSUM) algorithm in [45]. This algorithm is a postprocessing technique based on statistics which brings intelligence in diagnosis. The principle is as follows. At each sample, based on the values of the fault indices, the likelihood of each faulty state is evaluated. This likelihood is cumulated over several samples in CUSUM functions associated with each fault. Then, by comparing the CUSUM functions with each other, it is possible to retrieve the most likely state of the drive. In case of fault, a fault flag (FF) is set high. The advantage of the CUSUM algorithm is an improved robustness for FDI. Moreover, the algorithm offers a high flexibility regarding the number and the nature of fault indices, what can allow an extension of FDI to other faults.

\section{DRIVE MODEL AND CONTROL PARAMETERS}

The topology under study is depicted in Fig. 2. The drive is composed of a single energy source, a six-leg inverter and a three-phase open-end winding PMSM. The two subscripts of the switches refer to their corresponding phase and to the location of the switch with respect to the phase terminals.

\section{A. PMSM model}

Neglecting the effects of saliency and magnetic saturation, the model of PMSMs is given by:

$$
\left[\begin{array}{l}
V_{a} \\
V_{b} \\
V_{c}
\end{array}\right]=R_{s}\left[\begin{array}{l}
I_{a} \\
I_{b} \\
I_{c}
\end{array}\right]+\left[L_{a b c}\right] \frac{d}{d t}\left[\begin{array}{c}
I_{a} \\
I_{b} \\
I_{c}
\end{array}\right]+\left[\begin{array}{c}
E_{a} \\
E_{b} \\
E_{c}
\end{array}\right]
$$

where $V_{a b c}$ are the voltages at the machine terminals, $R_{s}$ the stator resistance, $I_{a b c}$ the phase currents, $\left[L_{a b c}\right]$ the inductance matrix and $E_{a b c}$ the electromotive force (emf) due to the permanent magnets.

The electrical equations of open-end winding PMSMs expressed in the synchronous reference frame are given by (2) and (3):

$$
\left[\begin{array}{l}
V_{0} \\
V_{d} \\
V_{q}
\end{array}\right]=R_{s}\left[\begin{array}{l}
I_{0} \\
I_{d} \\
I_{q}
\end{array}\right]+\left[\begin{array}{ccc}
L_{0} & 0 & 0 \\
0 & L_{d} & 0 \\
0 & 0 & L_{q}
\end{array}\right] \frac{d}{d t}\left[\begin{array}{c}
I_{0} \\
I_{d} \\
I_{q}
\end{array}\right]+\left[\begin{array}{c}
E_{0} \\
E_{d} \\
E_{q}
\end{array}\right]
$$

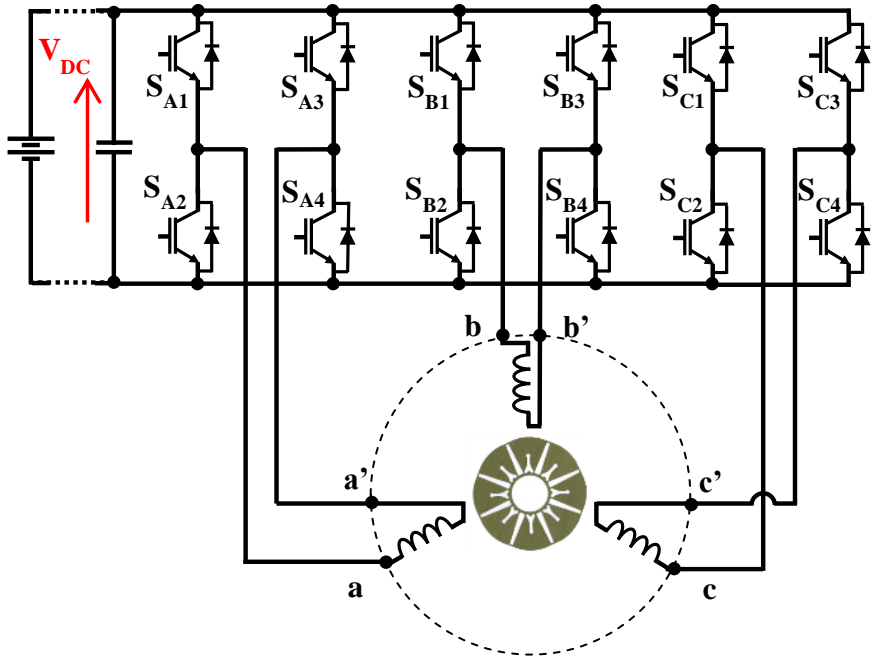

Fig. 2. Drive topology composed of a single energy source, a six-leg inverter and a three-phase PMSM with open-end windings.

$$
\left[\begin{array}{c}
E_{0} \\
E_{d} \\
E_{q}
\end{array}\right]=\omega_{e}\left[\begin{array}{c}
e\left(3 \theta_{e}\right) \\
-L_{q} I_{q} \\
L_{d} I_{d}+\psi_{M, 1}
\end{array}\right]
$$

where $L_{0}$ is the zero-sequence inductance, $L_{d}$ and $L_{q}$ the $d$ and $q$-axis inductances respectively, $\omega_{e}$ the electrical pulsation and $\theta_{e}$ the electrical position. It is assumed that the electromotive force is only composed of fundamental and third-harmonic components; therefore the zero-sequence emf is a function of $3 \theta_{e}$, whereas the $q$-axis emf depends on the value of the fundamental flux linkage due to the permanent magnets $\psi_{M, 1}$.

\section{B. Inverter model}

In healthy operation, the inverter output voltage with respect to phase $x(x \in\{a, b, c\})$ is equal to:

$$
V_{x}=\left\{\begin{array}{ccc}
+V_{D C} & \text { if } \quad S_{X 1}=S_{X 4}=1 \\
0 & \text { if } \quad S_{X 1}=S_{X 3}=1 \\
0 & \text { if } \quad S_{X 2}=S_{X 4}=1 \\
-V_{D C} & \text { if } \quad S_{X 2}=S_{X 3}=1
\end{array}\right.
$$

with $V_{D C}$ the DC-link voltage and $S_{X Y}$ the state of the switch associated with phase $x$ and located at $Y(Y \in\{1,2,3,4\})$, '1' being the 'on' state.

Eq. (4) is no longer valid in case of inverter fault. However, the system of equations in faulty operation depends on the nature of the fault.

In case of broken wire or connection, the corresponding phase current is equal to zero and the phase voltage is equal to the sum of the emf and the voltage induced by the magnetic couplings, i.e. according to (1).

In case of driver or gate-command-signal failures, the voltage equation depends on the switches that are involved in the fault. Eq. (4) can be rewritten for every combination of failures. For example, in case $S_{X 1}$ or $S_{X 4}$ fails open, it is no longer possible to enforce $V_{x}=+V_{D C}$. However, as far as the free-wheeling diodes are healthy, the only general statement is:

$$
-V_{D C} \leq V_{x} \leq V_{D C}
$$




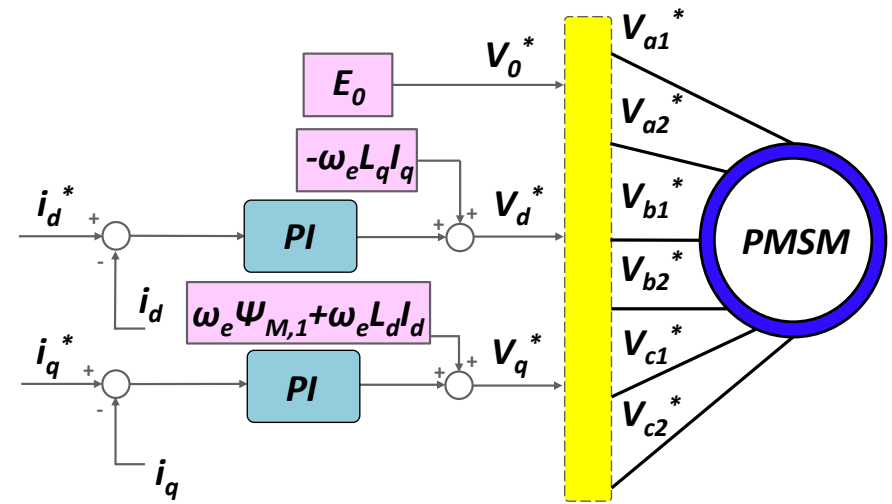

Fig. 3. Block diagram of the control scheme.

Consequently, depending on the faulty switches and the induced voltage, no current, a controlled current or an uncontrolled current can be observed in the faulty phase.

\section{Control loops}

The block diagram of the control scheme is given in Fig. 3. A conventional control of the $d$ - and $q$-axis currents is used, i.e. a field-oriented control with proportional-integral (PI) controllers and compensated emf.

Regarding the zero-sequence component, a particularity consists in only compensating the emf. This allows an operation with a null zero-sequence current in healthy operation. Moreover, this allows an inherent fault-tolerant control in case of open-circuit faults. As the zero-sequence current is not controlled, the $d q$ controllers are able to reject a part of the components at $2 \omega_{e}$ which appear upon the fault occurrence, and therefore the torque ripple is reduced compared to three-phase star-connected machines.

TABLE I: DRIVE PARAMETERS

\begin{tabular}{|c|c|}
\hline Parameter & Value \\
\hline \hline$R_{s}$ & $0.475 \Omega$ \\
\hline$L_{d q}$ & $8.4 \mathrm{mH}$ \\
\hline$L_{0}$ & $0.35 \mathrm{mH}$ \\
\hline$\psi_{M, 1}$ & $0.31 \mathrm{~V} \mathrm{~s} / \mathrm{rad}$ \\
\hline$e\left(3 \theta_{e}\right)_{\text {peak }}$ & $0.010 \mathrm{~V} \mathrm{~s} / \mathrm{rad}$ \\
\hline$N_{p p}$ & 4 \\
\hline$I_{d q, \max }$ & $36 \mathrm{~A}$ \\
\hline$V_{D C}$ & $200 \mathrm{~V}$ \\
\hline$T_{s}$ & $25 \mu \mathrm{s}$ \\
\hline
\end{tabular}

\section{Control in Faulty Operation}

The following faults are considered in this paper: a singleswitch open-circuit fault and a single-phase open-circuit fault. The drive has been modeled in order to simulate the aforementioned faults. It is also possible to operate the drive of the test bed under these faulty conditions, what allows a validation of the model. The drive parameters are given in Table I.

Fig. 4 shows the comparison of the phase currents obtained by simulations and by experiments for a single-switch opencircuit fault $\left(S_{A 1}\right)$. This fault will be referred to as SWA1O in what follows.

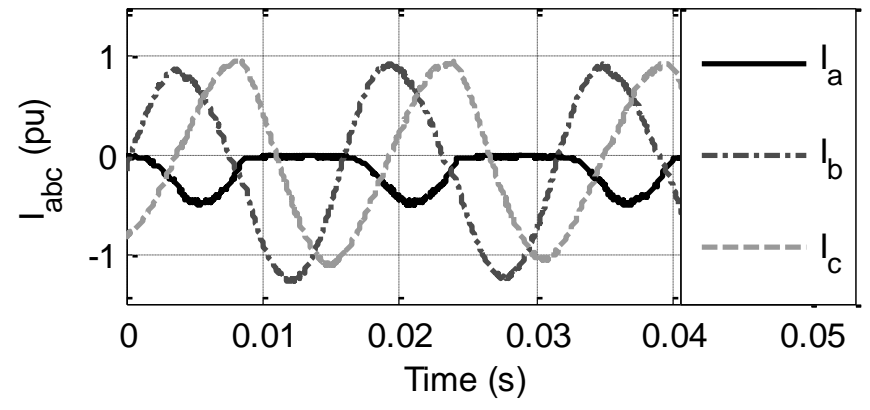

(a) Simulation results.

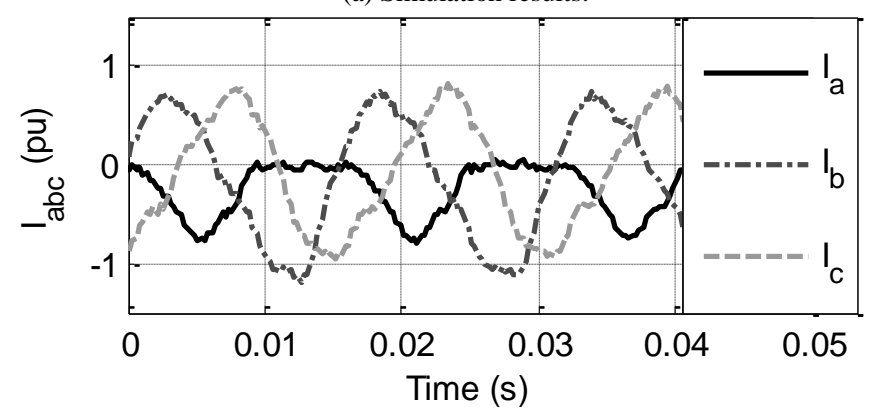

(b) Experimental results.

Fig. 4. Comparison of the phase currents obtained by simulations and by experiments with an open-switch fault (SWA1O) with $\omega_{\mathrm{m}}=100 \mathrm{rad} \mathrm{s}^{-1}$ and $\mathrm{I}_{\mathrm{a}}^{*}=0.7 \mathrm{pu}$.

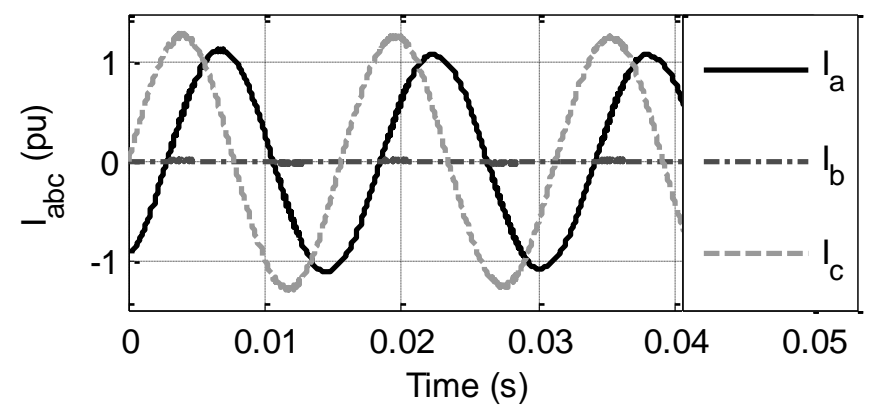

(a) Simulation results.

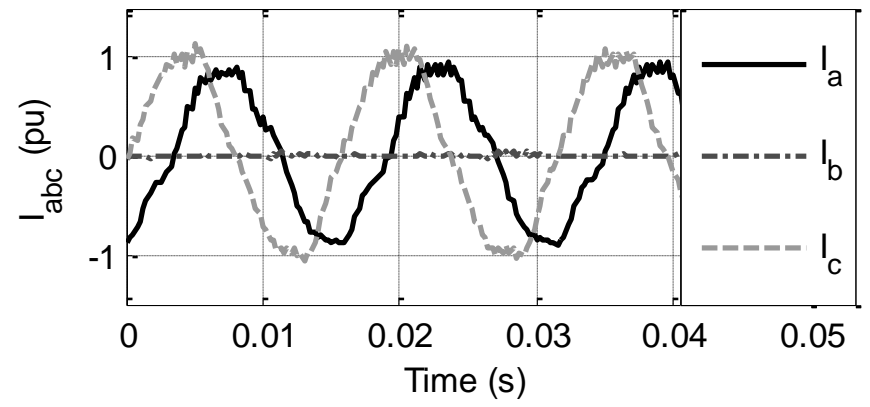

(b) Experimental results.

Fig. 5 Comparison of the phase currents obtained by simulations and by experiments with an open-circuit fault (BO) with $\omega_{\mathrm{m}}=100 \mathrm{rad} \mathrm{s}^{-1}$ and $\mathrm{I}_{\mathrm{q}}^{*}=0.7 \mathrm{pu}$.

Both plots clearly show that the faulty phase current is distorted. In particular, the current only takes negative values. This is due to the inverter output voltage that can no longer be equal to $+V_{D C}$ when the phase current is positive. Consequently, the inverter output voltage cannot be greater than the induced voltage and the current remains equal to zero for a half period. 


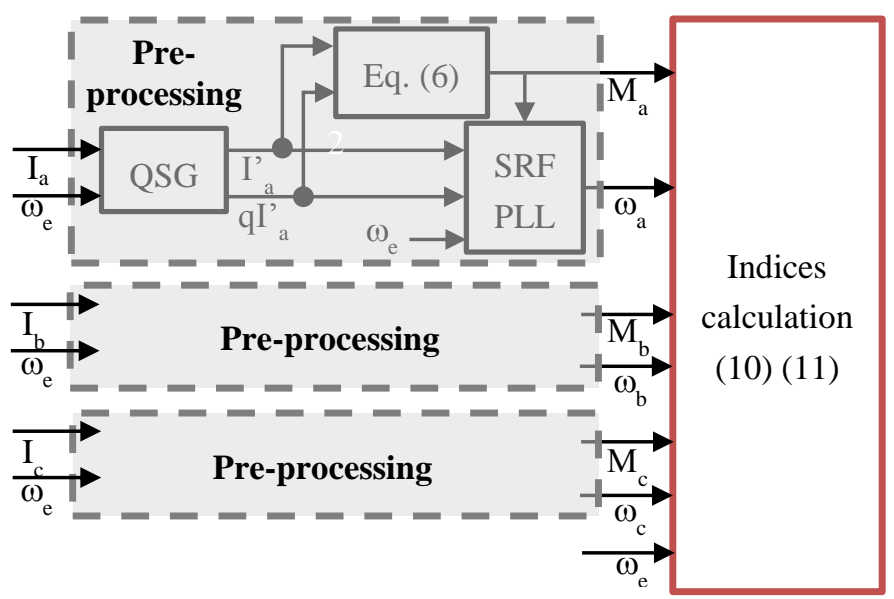

Fig. 6. Pre-processing of the phase currents for the calculation of the fault indices.

During the other half period, the current returns to the DClink via the free-wheeling diode and thus the voltage reference is well applied to the machine terminals. It has to be noted that the same analysis is valid in case $S_{A 4}$ fails open. Hence, without additional isolation procedure, the discrimination of the fault is not possible: the polarity of the current gives only information on one faulty pair, i.e. $\left(S_{A 1}, S_{A 4}\right)$ if the current polarity is negative or $\left(S_{A 2}, S_{A 3}\right)$ if the current polarity is positive.

It can also be observed in Fig. 4 that there are differences regarding the magnitude of the simulated and measured currents. The currents of the healthy phases are larger in the simulations and conversely for the current of the faulty phase.

Fig. 5 shows the comparison of the phase currents obtained through simulations and through experiments for an opencircuit fault in phase $b$. This fault will be referred to as BO in what follows. It can be observed that both plots are very similar. Additional harmonic components can be observed in the experimental results, in particular the third-, fifth- and seventh harmonic components that appear due to magnetic saturation when the machine is loaded. Further, due to the inherent fault-tolerant structure, the currents in the remaining phase increase to compensate for the fault.

Although the torque ripple is greatly reduced compared with the classical three-leg topology, a second-harmonic component can still be observed as the healthy currents have different magnitudes. This torque ripple can be eliminated by applying a control reconfiguration, such as in [39] or with a resonant controller as in [46].

\section{FAULT INDICES}

In the previous section, the characteristics of the faults have been analyzed. Unbalanced phase currents are a common characteristic to the faults under study. The faulty phase current is much lower than the healthy currents, the latter being nearly equals in magnitude.

The difference in frequency is another characteristic of the faults since the healthy-currents pulsation is equal to $\omega_{e}$, whereas the faulty-current pulsation in case of open-phase fault is equal to zero and finally the faulty-current pulsation in case of single-switch open-circuit fault alternates between $\omega_{e}$ and zero.

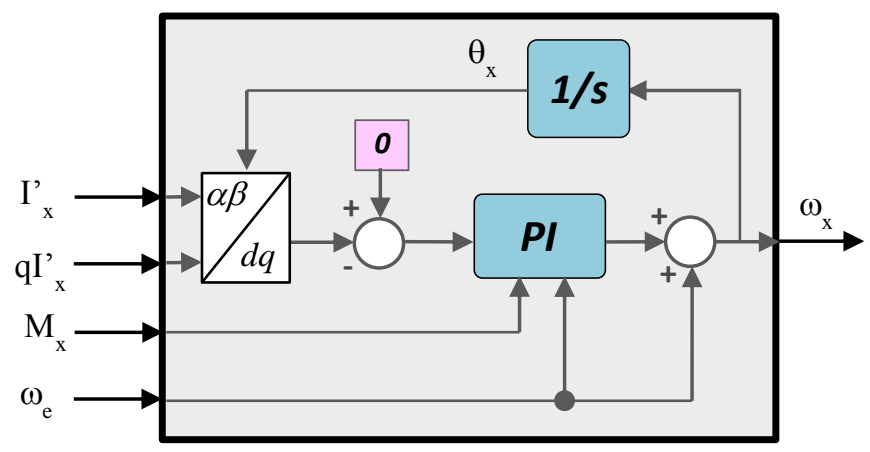

Fig. 7. Improved SRF PLL accounting for load and speed variations.

In what follows, signal-processing techniques which allow the extraction of the magnitude and the frequency of the phase currents are used. These techniques are a quadrature-signal generator (QSG) and a phase-locked loop (PLL). The principle is depicted in Fig. 6. This pre-processing eventually leads to the derivation of suitable indices for fault detection and isolation.

\section{A. Envelope Detection}

The magnitude of the phase currents is obtained with the structure proposed in [43] and adapted in [39] for PMSMs. Adaptive filters allow the isolation of the fundamental component of each phase current and the quadrature-signal generation. Hence, the signal envelope $M_{x}$ of each phase current is obtained by calculating:

$$
M_{x}=\sqrt{\left(I_{x}^{\prime}\right)^{2}+\left(q I_{x}^{\prime}\right)^{2}}
$$

where $I_{x}^{\prime}$ is the band-pass filtered current of phase $x$ and $q I_{x}^{\prime}$ is the low-pass filtered and $90^{\circ}$-shifted current of phase $x$.

\section{B. Phase-Locked Loop}

To take further benefits of the QSG, a synchronousreference-frame (SRF) PLL is used for the instantaneouspulsation estimation [44]. In [39], it is shown that the response of a PLL with constant gains is load- and frequencydependent, making difficult the prediction of the PLL response.

To improve this scheme, the implementation of Fig. 7 is proposed. The output of the PLL is the instantaneous frequency $\omega_{x}$, which is the sum of the electrical pulsation and the PI controller output. The feedforward term $\omega_{e}$ allows improving the dynamic response as only deviations with respect to the electrical pulsation will be observed.

The calculations of the PLL gains are given in [44]. For a given bandwidth $\omega_{P L L}$ and damping factor $\zeta_{P L L}$, these gains are equal to:

$$
\begin{aligned}
& K_{P, P L L}=\frac{2 \omega_{P L L} \zeta_{P L L}}{M_{x}} \\
& K_{I, P L L}=\frac{K_{P, P L L} \omega_{P L L}}{2 \zeta_{P L L}}
\end{aligned}
$$

Further, to avoid a drift of the PLL output in case the machine is operated at zero current, the PI controller is inhibited at low current magnitudes. 


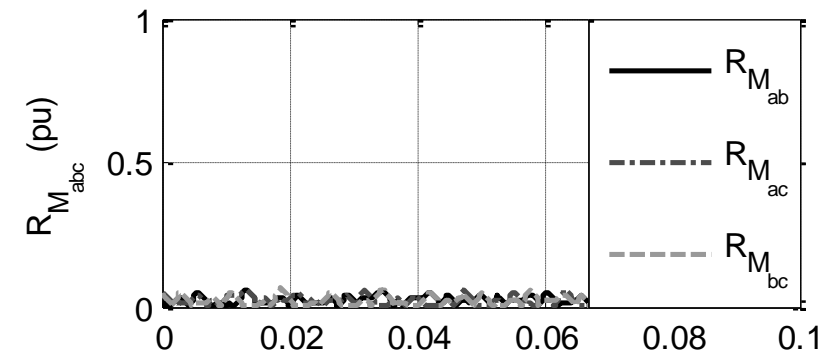

(a) Magnitude indices (simulation results).

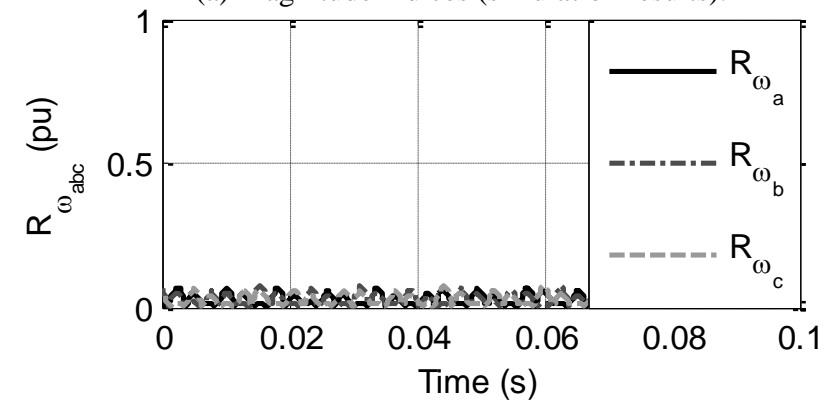

(c) Frequency indices (simulation results).

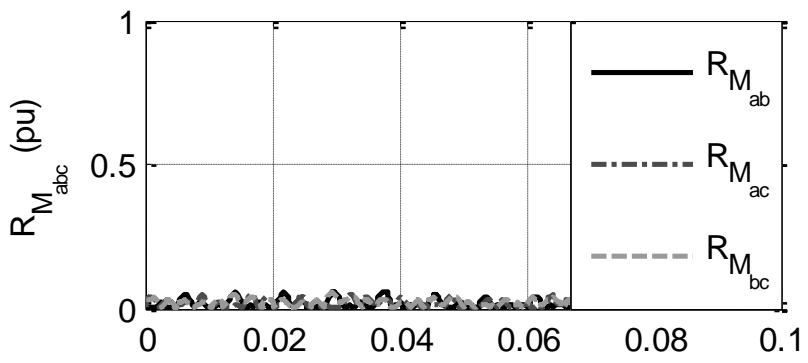

(b) Magnitude indices (expфrimental results).

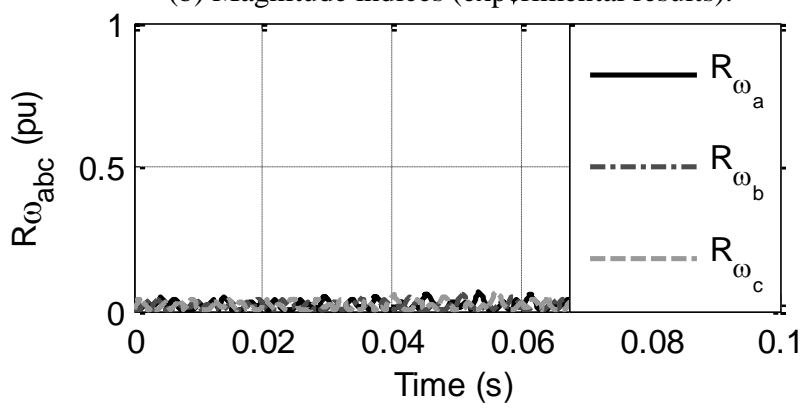

(d) Frequency indices (experimental results).

Fig. 8. Comparison of the fault indices obtained by simulations and by experiments in healthy operation $\quad$ with $\omega_{\mathrm{m}}=100 \mathrm{rad} \mathrm{s}^{-1}$ and $\mathrm{I}_{\mathrm{q}}^{*}=0.7 \mathrm{pu}$.

Consequently, the PLL is also inhibited in case of openphase fault, but not in case of single-switch open-circuit fault. The frequency estimation allows thus the nature of the fault to be isolated.

Finally, as the objective is to detect deviations compared with the electrical pulsation, the magnitude of this deviation should not depend on the speed. This can be achieved by choosing a PLL bandwidth such that:

$$
\omega_{P L L}=\omega_{e}
$$

\section{Indices Calculation}

Suitable fault indices are obtained if the following guidelines are achieved:

- the values of the indices are close to zero in healthy operation and are large in case of fault;

- the values of the indices in case of fault have to allow the isolation of these faults;

- the indices are insensitive to the operating conditions (speed and load).

Based on the phase-current envelopes $M_{x}$ and instantaneous pulsations $\omega_{x}$, the following indices are proposed:

$$
\begin{aligned}
R_{M_{a b}} & =\left|\frac{M_{a}-M_{b}}{\max \left(M_{a}, M_{b}, M_{c}\right)}\right| \\
R_{M_{a c}} & =\left|\frac{M_{a}-M_{c}}{\max \left(M_{a}, M_{b}, M_{c}\right)}\right| \\
R_{M_{b c}} & =\left|\frac{M_{b}-M_{c}}{\max \left(M_{a}, M_{b}, M_{c}\right)}\right| \\
R_{\omega_{a}} & =\left|\frac{\omega_{e}-\omega_{a}}{\omega_{e}}\right| \\
R_{\omega_{b}} & =\left|\frac{\omega_{e}-\omega_{b}}{\omega_{e}}\right| \\
R_{\omega_{c}} & =\left|\frac{\omega_{e}-\omega_{c}}{\omega_{e}}\right|
\end{aligned}
$$

The magnitude indices (10) and frequency indices (11) are theoretically equal to zero in case the currents are balanced. This can be observed in Fig. 8 in which the fault indices in healthy operation are plotted for steady state. The indices are close to zero and there is a good concordance between simulations and experiments.

Fig. 9 shows the fault indices in case of single-switch opencircuit fault (SWA1O). It can be observed than three fault indices are strongly affected, i.e. $R_{M_{a b}}, R_{M_{a c}}$ and $R_{\omega_{a}}$, which are all the indices associated with the faulty phase.

As the system alternates between a healthy half-period and a faulty half-period, the indices alternate between large and low values as well. It can also be observed that the simulation and experimental results slightly differ since the minimum values of $R_{M_{a b}}$ and $R_{M_{a c}}$ are lower in the experiments. This can be explained by the current waveforms of Fig. 4 . As the experimental results show that the healthy half-period is closer to the currents in healthy operation, the magnitude indices based on the unbalance are also lower within this half-period.

Another observation from Fig. 9(b) and (d) is that, although three indices are strongly affected, the other indices can be slightly affected as well. This makes difficult the use of threshold-based techniques since the thresholds can hardly be defined without intensive testing.

Fig. 10 shows the fault indices in case of open-phase fault (BO). It can be observed than two fault indices are strongly affected, i.e. $R_{M_{a b}}$ and $R_{M_{b c}}$, which are the magnitude indices associated with the faulty phase. As the PLL is inhibited at low current magnitude, $R_{\omega_{b}}$ remains unaffected by the fault. The comparison between simulations and experiments shows a very good concordance. 


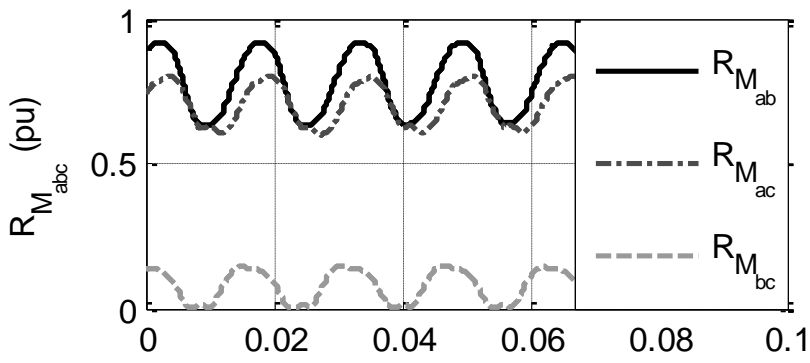

(a) Magnitude indices (simulation results).

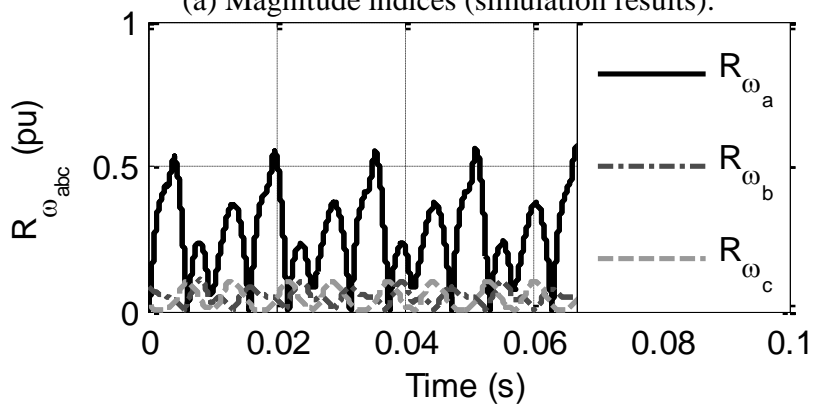

(c) Frequency indices (simulation results).

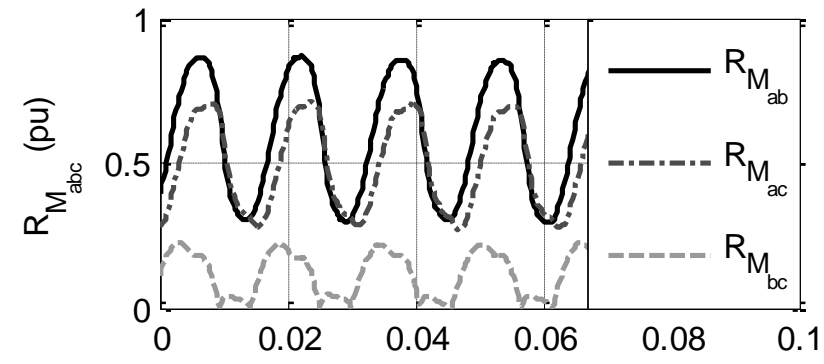

(b) Magnitude indices (experimental results).

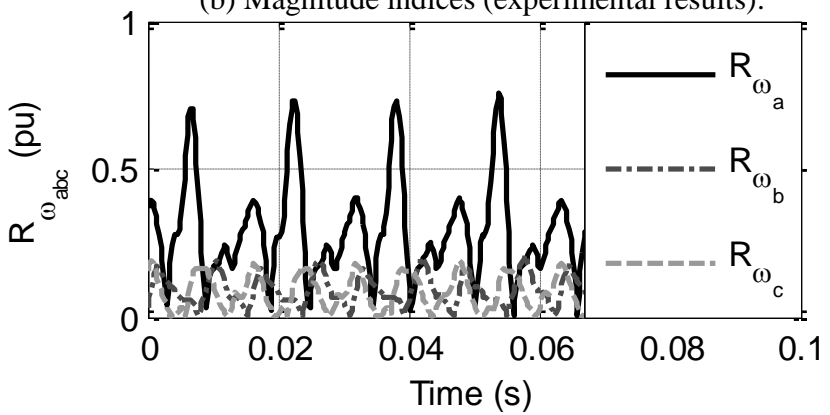

(d) Frequency indices (experimental results).

Fig. 9. Comparison of the fault indices obtained by simulations and by experiments in operation with an open-switch fault in phase $a$ $(\mathrm{SWA1O})$ and $\omega_{\mathrm{m}}=100 \mathrm{rad} \mathrm{s}^{-1}$ and $\mathrm{I}_{\mathrm{q}}^{*}=0.7 \mathrm{pu}$.

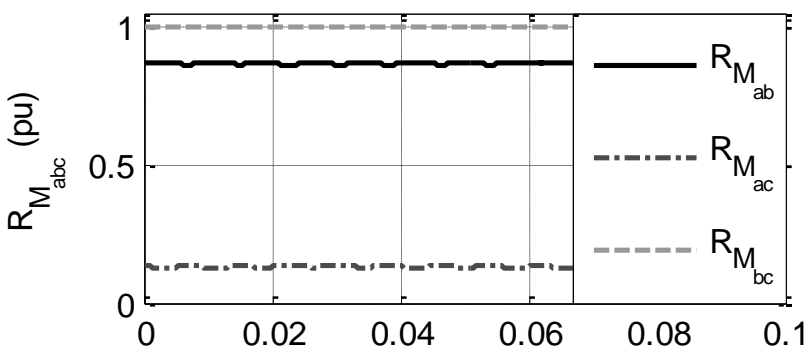

(a) Magnitude indices (simulation results).

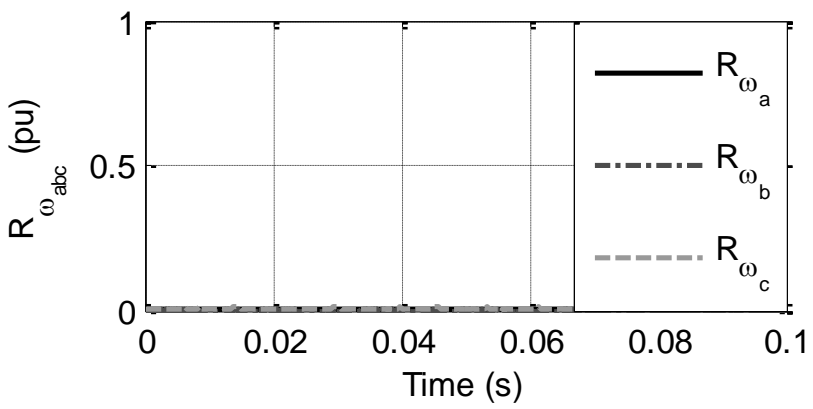

(c) Frequency indices (simulation results).

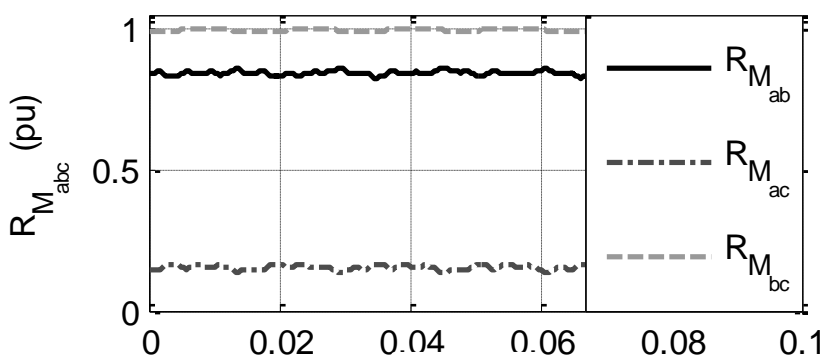

(b) Magnitude indices (experimental results).

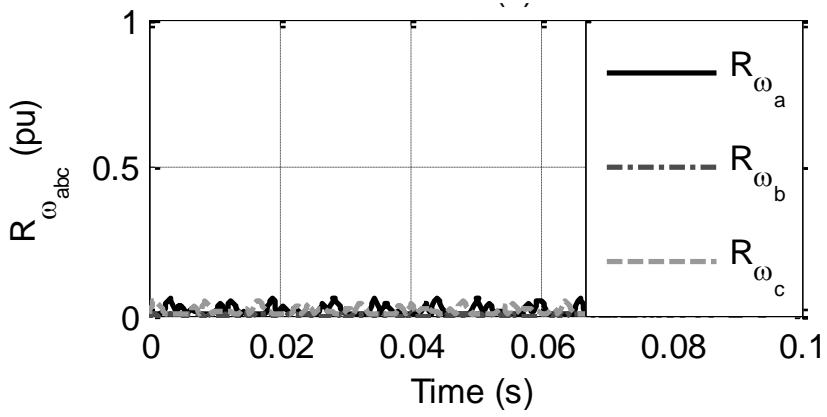

(d) Frequency indices (experimental results).

Fig. 10. Comparison of the fault indices obtained by simulations and by experiments in operation with an open-circuit in phase $b$ (BO) and $\omega_{\mathrm{m}}=100 \mathrm{rad} \mathrm{s}^{-1}$ and $\mathrm{I}_{\mathrm{q}}^{*}=0.7 \mathrm{pu}$.

\section{DECISION SYSTEM}

The objective of the decision system is to process the fault indices in order to make the decision that a fault has occurred and to isolate this fault, as depicted in Fig. 11 for the faults under study. To do so, the cumulative sum (CUSUM) algorithm is proposed [45]. A summary of the general theory is given in the following sections, as well as simplifications for implementation purposes.

\section{A. CUSUM theoretical background}

Generally, fault detection and isolation of several faults can be based on multiple indices. An appropriate number of indices $n_{R}$ has to be chosen in order to isolate a certain number of faults $n_{f}$. 


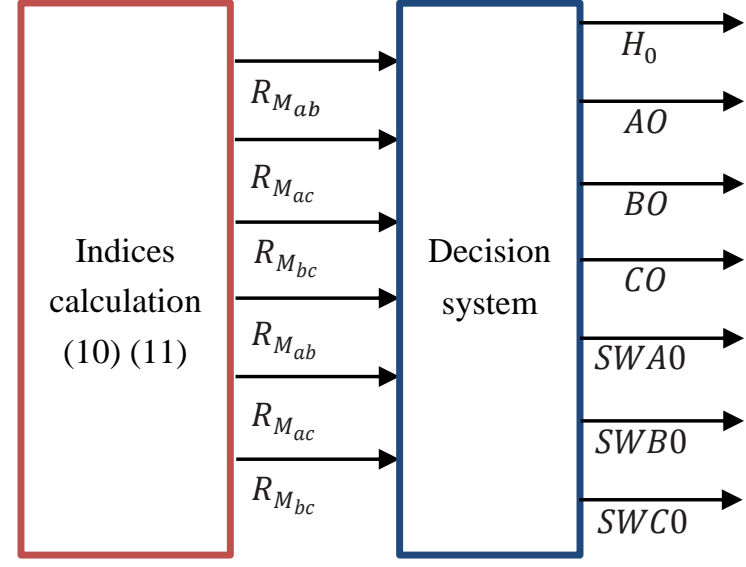

Fig. 11. Processing of the fault indices by the decision system.

Table II. Incidence table for a general case.

\begin{tabular}{|c|c|c|c|c|}
\hline & Fault 1 & Fault 2 & $\cdots$ & Fault $\boldsymbol{n}_{\boldsymbol{f}}$ \\
\hline \hline Index 1 & $\mathrm{X}$ & $\mathrm{X}$ & $\cdots$ & $\mathrm{X}$ \\
\hline Index 2 & $\mathrm{X}$ & 0 & $\cdots$ & 0 \\
\hline$\vdots$ & $\vdots$ & $\vdots$ & $\ddots$ & $\vdots$ \\
\hline Index $\boldsymbol{n}_{\boldsymbol{R}}$ & 0 & $\mathrm{X}$ & $\cdots$ & 0 \\
\hline
\end{tabular}

The sensitivity of the fault indices to the faults can be expressed in an incidence table, as shown in Table II. A cross means that the index has a significant sensitivity to the corresponding fault, whereas a zero means that the sensitivity to the fault is low.

At each sample $k$, the $n_{R}$ values of the fault indices can be expressed as:

$$
[r(k)]=\left[r_{0}(k)\right]+\left[r_{f}(k)\right]
$$

where $[r(k)],\left[r_{0}(k)\right]$ and $\left[r_{f}(k)\right]$ are $n_{R}$-dimensional column vectors representing the instantaneous values of the fault indices, their values in healthy operation and the additional contribution due to the fault respectively. Since the set of indices allows fault detection and isolation, $\left[r_{f}(k)\right]$ can be further described as:

$$
\left[r_{f}(k)\right]=\sum_{j=1}^{n_{f}} \epsilon_{j}(k)\left[\Gamma_{j}\right]
$$

where $\epsilon_{j}$ is a scalar representing the magnitude of the fault $j$ at time $k$ and $\left[\Gamma_{j}\right]$ is a $n_{R}$-dimensional column vector indicating the direction of the fault $j\left(j \in\left\{1, \ldots, n_{f}\right\}\right)$. $\left[\Gamma_{j}\right]$ is actually the $j$ th column vector of the incidence matrix $[I]$, which is obtained by quantifying the elements of the incidence table.

There are several methods to derive the incidence matrix. Two are discussed: the knowledge-based method and the statistics-based method.

The knowledge-based method is simple for three-phase starconnected machines. It consists in noting that, in case of fault, the faulty phase current is equal to zero during a part of the period and consequently the healthy phase currents are equal in magnitude during this part of the period, yielding $R_{M_{a b}}=$ $1, R_{M_{a c}}=1$ and $R_{M_{b c}}=0$. This analysis is not valid for the proposed topology, as shown in Fig. 10, where $R_{M_{a b}}=1$, $R_{M_{a c}}=0.86$ and $R_{M_{b c}}=0.14$.

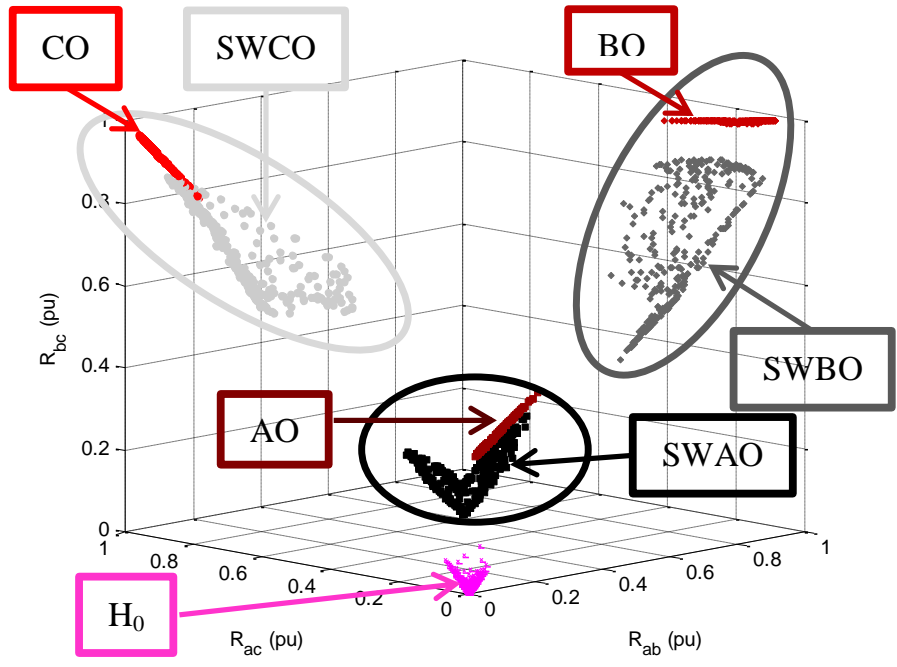

Fig. 12. Envelope-based fault indices for the six faults under study.

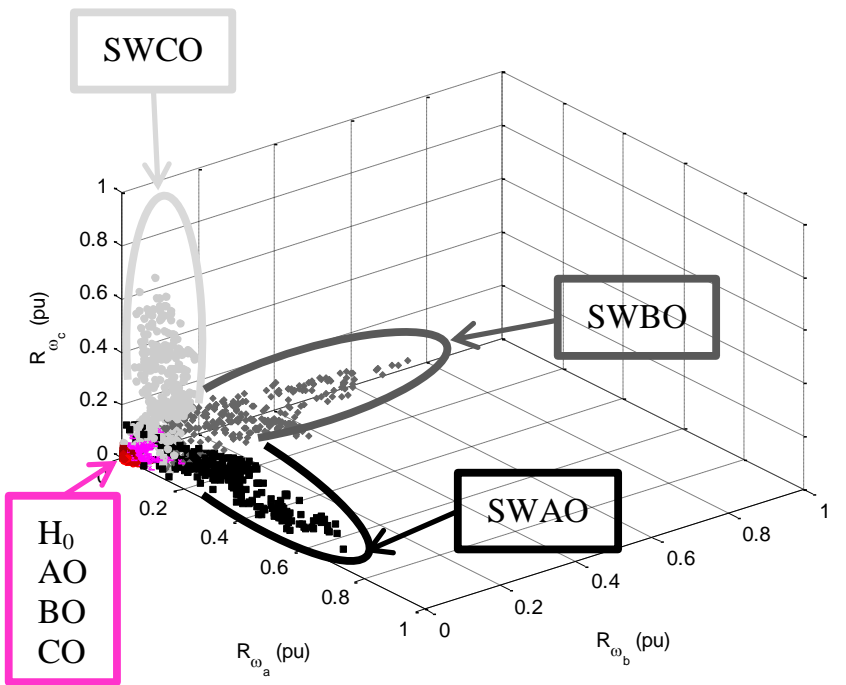

Fig. 13. Frequency-based fault indices for the six faults under study.

Moreover, these values are not constant and change with the operating conditions. Therefore, another solution consists in using a statistics-based method, in which intensive simulations/testing are required to find accurate values of the mean and standard deviation of the indices in fault conditions.

In Fig. 12 and Fig. 13, values of the fault indices for various operating conditions and all faults under study have been plotted. The results are represented into two three-dimensional spaces. The former is dedicated to the envelope-based indices and the latter is dedicated to frequency-based indices. Four separate distributions can be observed in both spaces.

In Fig. 12, there are: one distribution close to the origin, which corresponds to the healthy situation $\left(H_{0}\right)$; three distributions having high components along two axes and a low component along the third axis. The latter distributions correspond to faults in each phase.

On the other hand, in Fig. 13, the distribution close to the origin includes four states: the healthy operation $\left(H_{0}\right)$ and the open-phase faults ( $\mathrm{AO}, \mathrm{BO}$ and $\mathrm{CO}$ ). The distributions associated with the single-switch open-circuit faults are directed along the axis of the corresponding fault index, e.g. along the $R_{\omega_{a}}$ axis for SWAO. 
Table III. Incidence matrix for inverter faults.

\begin{tabular}{|c|c|c|c|c|c|c|}
\hline & AO & BO & CO & SWAO & SWBO & SWCO \\
\hline$R_{M_{a b}}$ & 1 & 1 & 0 & 1 & 1 & 0 \\
\hline$R_{M_{a c}}$ & 1 & 0 & 1 & 1 & 0 & 1 \\
\hline$R_{M_{b c}}$ & 0 & 1 & 1 & 0 & 1 & 1 \\
\hline$R_{\omega_{a}}$ & 0 & 0 & 0 & 0.5 & 0 & 0 \\
\hline$R_{\omega_{b}}$ & 0 & 0 & 0 & 0 & 0.5 & 0 \\
\hline$R_{\omega_{c}}$ & 0 & 0 & 0 & 0 & 0 & 0.5 \\
\hline
\end{tabular}

In the statistics-based method, the mean value of the fault indices is used to generate the incidence matrix. The drawback of this method is that the process can be burdensome and time consuming. Therefore, a simplified analysis is proposed.

Actually, it is enough to seek for the general direction of the faults if the distance between their statistical distributions is large. The direction of the faults in phase $a$ is thus set to $\left[\begin{array}{lll}1 & 1 & 0\end{array}\right]^{T}$ in the three-dimensional space dedicated to the envelope-based indices (results are immediate for the other phases). It is worth noticing that this choice yield a method equivalent to the knowledge-based analysis discussed previously.

As the values of the frequency indices are lower than those of the magnitude indices, the direction of the faults is set to 0.5 , which corresponds approximately to the ratio of the mean values of the distributions in both spaces.

The subsequent matrix $[\Pi]$ obtained from the analysis is given in Table III.

Regarding the magnitude of the faults, it is convenient to choose only one fault magnitude to reduce the number of parameters. In what follows, $\epsilon_{j}=0.5$ is chosen for all faults $j$. It can be verified that the values plotted in Fig. 12 and Fig. 13 are then consistent with (13) and Table III.

The problem of fault detection and isolation is to assess the drive condition, which is the healthy state $H_{0}$ or one of the faulty states $H_{j}$. The CUSUM algorithm allows evaluating the likelihood of each state at each sample and cumulates this likelihood over several samples, improving thus the robustness of the FDI. To do so, an assumption that the fault indices are distributed according to Gaussian sequences is made. Then, the algorithm is based on the log-likelihood ratio $s_{j, l}$ between two states $j$ and $l$, given by:

$$
s_{j, l}(k)=\ln \frac{p_{j}([r(k)])}{p_{l}([r(k)])}
$$

where $p_{j}\left(p_{l}\right)$ denotes the probability density function of $[r(k)]$ under the state $H_{j}\left(H_{l}\right)$.

Under the Gaussian hypothesis, (14) is given by [45]:

$$
s_{j, l}(k)=\left(\left[\mu_{j}\right]-\left[\mu_{l}\right]\right)^{T}[\Sigma]^{-1}\left([r(k)]-\frac{\left[\mu_{j}\right]+\left[\mu_{l}\right]}{2}\right)
$$

where $\left[\mu_{j}\right]\left(\left[\mu_{l}\right]\right)$ is the mean value of the fault indices vector under the state $j(l)$ and $[\Sigma]$ is the variance matrix.

From (14), the problem of fault isolation can be simplified by noticing that:

$$
s_{j, l}(k)=s_{j, 0}(k)-s_{l, 0}(k)
$$

which means that only $n_{f}$ functions have to be calculated. Each faulty state is compared with the healthy state and the larger log-likelihood ratio (LLR) indicates the most likely state.

To improve the robustness of the FDI method, the CUSUM algorithm is not based directly on the LLR, but on the sum of successive values of this LLR. Hence, a CUSUM function $g_{j}$ is associated with each fault $j$. This function is given by:

$$
g_{j, 0}(k)=\max \left(0, g_{j, 0}(k-1)+s_{j, 0}(k)\right)
$$

with $g_{0,0}(k)=0$ (healthy state is used as reference). Eq. (17) acts like an integration of the LLR. As long as there is no fault, the likelihood of the healthy state is the highest and all LLRs are negative, therefore all CUSUM functions remain equals to zero. Upon a fault occurrence, some LLRs will be positive and thus their corresponding CUSUM functions start increasing.

Modified CUSUM functions can be used to perform the fault detection and isolation at once. This modified function is given by (18).

$$
g_{j}^{*}(k)=\min _{0 \leq l \neq j \leq n_{f}}\left(g_{j, 0}(k)-g_{l, 0}(k)\right)
$$

Eq. (18) ensures that, at a given time, only one function is positive, which is the most likely state. The decision that the faulty state $j$ holds is made in case the modified CUSUM function $g_{j}^{*}(k)$ crosses a user-chosen threshold $h_{F D I, l}$. This threshold influences the detection delay $\Delta t_{F D I, l}$, which can be estimated as follows:

$$
\Delta t_{F D I, l}=T_{s}\left(\frac{h_{F D I, l}}{\min _{0 \leq l \neq j \leq n_{f}} \kappa_{l, j}}\right)
$$

where $T_{s}$ is the sampling period and $\kappa_{l, j}$ is the KullbackLeibler information defined as [47]:

$$
\kappa_{l, j}=\frac{1}{2}\left(\left[\mu_{j}\right]-\left[\mu_{l}\right]\right)^{T}[\Sigma]^{-1}\left(\left[\mu_{j}\right]-\left[\mu_{l}\right]\right)
$$

Eq. (20) gives information on the distance between the statistical distributions. Hence, if two states are close to each other, $\kappa_{l, j}$ will be low and the isolation time will be high accordingly. For example, regarding Fig. 12, the distributions of AO and SWAO are close. Therefore, without the frequency-based indices depicted in Fig. 13, the fault isolation would be difficult.

\section{B. CUSUM practical implementation}

The calculation of (15) requires the knowledge of $\left[\mu_{j}\right]$ for each fault $j$ and of $\left[\mu_{0}\right]$ for the healthy operation. As discussed in the previous section, the calculation of $\left[\mu_{j}\right]$ is given by:

$$
\left[\mu_{j}\right]=\epsilon_{j}\left[\Gamma_{j}\right]
$$

Although the theoretical values of the fault indices in healthy operation are equal to zero, it has been observed that residual values of a few percent's are possible. Therefore, $\left[\mu_{0}\right]$ is set to $\left[\mu_{0}\right]=0.05 *\left[\begin{array}{llllll}1 & 1 & 1 & 1 & 1 & 1\end{array}\right]^{\mathrm{T}}$.

Next, it is practically inconvenient to need the variance matrix $[\Sigma]$. Firstly because this matrix changes with the nature of the fault; it is difficult to take it into account. 


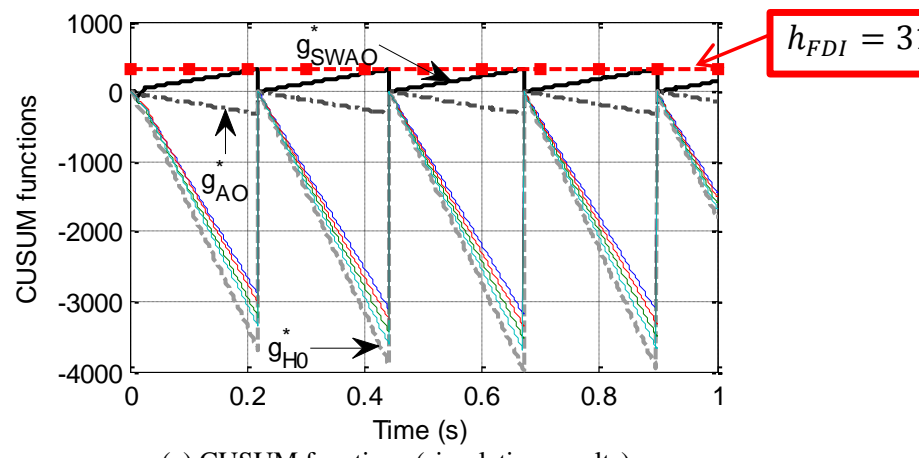

(a) CUSUM functions (simulation results).

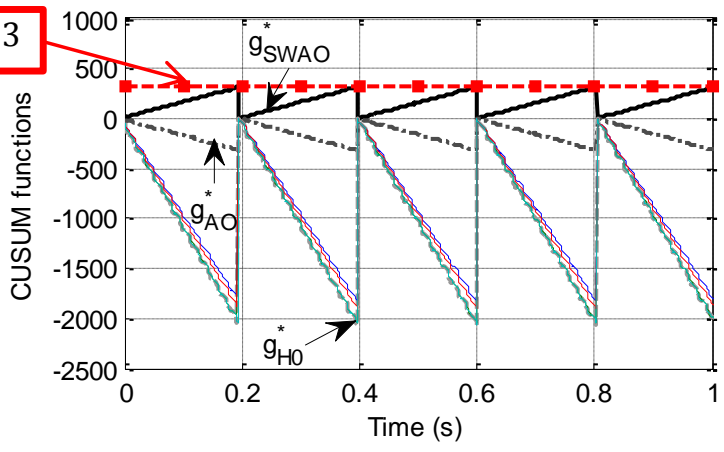

(b) CUSUM functions (experimental results).

Fig. 14. CUSUM functions obtained by simulations and by experiments in operation with SWA1O and $\omega_{\mathrm{m}}=100 \mathrm{rad} \mathrm{s}$ and I ${ }_{\mathrm{q}}^{*}=0.7 \mathrm{pu}$.

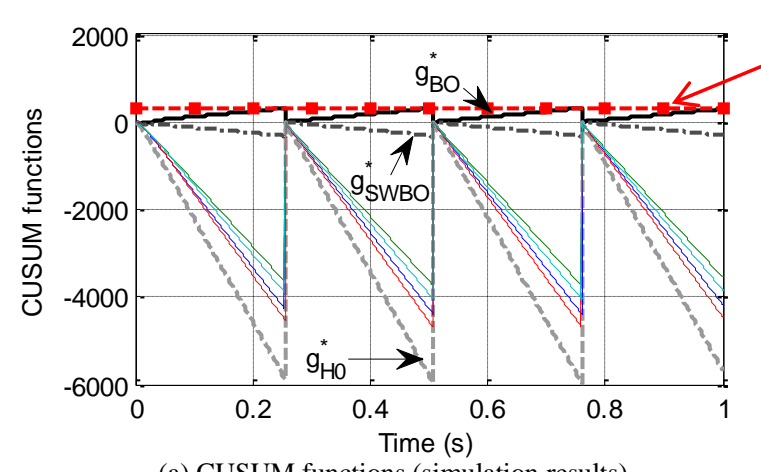

(a) CUSUM functions (simulation results).

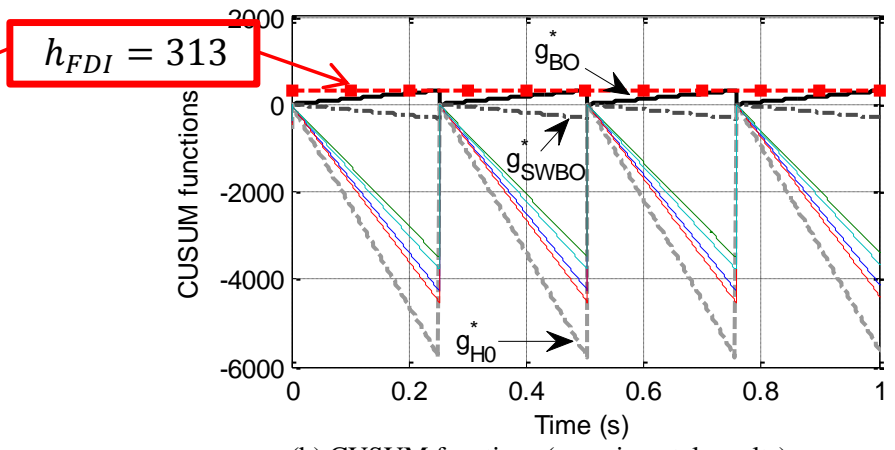

(b) CUSUM functions (experimental results).

Fig. 15. CUSUM functions obtained by simulations and by experiments in operation with $\mathrm{BO}$ and $\omega_{\mathrm{m}}=100 \mathrm{rad} \mathrm{s}^{-1}$ and $\mathrm{I}_{\mathrm{q}}^{*}=0.7 \mathrm{pu}$.

Secondly because there might be differences between simulation and experimental results; this can make difficult the interpretation of experimental results. Consequently, the matrix $[\Sigma]$ is chosen equal to the identity matrix. This hypothesis does not affect much the FDI scheme, but simplifies the implementation.

The detection delay $\Delta t_{F D I, l}$ can be a priori different for all faults $l$. However, to reduce the number of parameters, the same detection delay $\Delta t_{F D I}$ is chosen for all faults.

The detection delay depends on $\kappa_{l, j}$. For the application under study, the lowest value is the distance between openphase faults and the single-switch open-circuit faults. For instance for phase $a$ :

$$
\kappa_{A O, S W A O}=0.0313
$$

For a sampling period $T_{S}$ equal to $25 \mu \mathrm{s}$ and for a detection delay $\Delta t_{F D I}$ equal to $0.25 \mathrm{~s}$, the detection threshold $h_{F D I}$ is calculated via (19):

$$
h_{F D I}=313
$$

Parameters of the FDI scheme are summarized in Table IV. These parameters are used for the tests of the following sections.

Fig. 14 shows the seven CUSUM functions corresponding to the six faulty states and to the healthy state in case of single-switch open-circuit fault (SWA1O). It can be observed that the function $g_{S W A O}^{*}$ is a positive and increasing function, meaning that the likelihood of this state is the highest. When the CUSUM function crosses the isolation threshold $h_{F D I}$, the functions are reinitialized, what allows observing the persistence of the fault.

\begin{tabular}{|c|c|}
\hline Parameter & Value \\
\hline PLL damping factor $\zeta_{P L L}$ & $\sqrt{2}$ \\
\hline PLL bandwidth $\omega_{P L L}$ & $\omega_{e}$ \\
\hline Incidence matrix $[\Pi]$ & See Table III \\
\hline Inverter faults magnitude $\epsilon$ & 0.5 \\
\hline $\begin{array}{l}\text { Mean value of the fault indices } \\
\text { in healthy operation }\left[\mu_{0}\right]\end{array}$ & $0.05 *\left[\begin{array}{llllll}1 & 1 & 1 & 1 & 1 & 1\end{array}\right]^{T}$ \\
\hline $\begin{array}{c}\text { Variance matrix of the fault } \\
\text { indices }[\Sigma]\end{array}$ & {$\left[n_{f} \times n_{f}\right]$ Identity matrix } \\
\hline$\Delta t_{F D I}$ & $0.25 \mathrm{~s}$ \\
\hline$h_{F D I}$ & 313 \\
\hline
\end{tabular}

Table IV. Parameters of the FDI scheme.

It can be observed than the second most likely states is AO, as it has been predicted by (22). The less likely state is the healthy state $H_{0}$.

Fig. 14(a) and (b) show simulation and experimental results respectively. It can be seen that the patterns are similar. It takes about $0.21 \mathrm{~s}$ to cross the isolation threshold in simulations, whereas it takes about $0.2 \mathrm{~s}$ in the experiments. This is in relatively good concordance with the detection delay that has been set to $\Delta t_{F D I}=0.25 \mathrm{~s}$.

Fig. 15 shows the seven CUSUM functions corresponding to the six faulty states and to the healthy state in case of openphase fault (BO). It can be observed that the function $g_{B O}^{*}$ is a positive and increasing function, meaning that the likelihood of this state is the highest. 


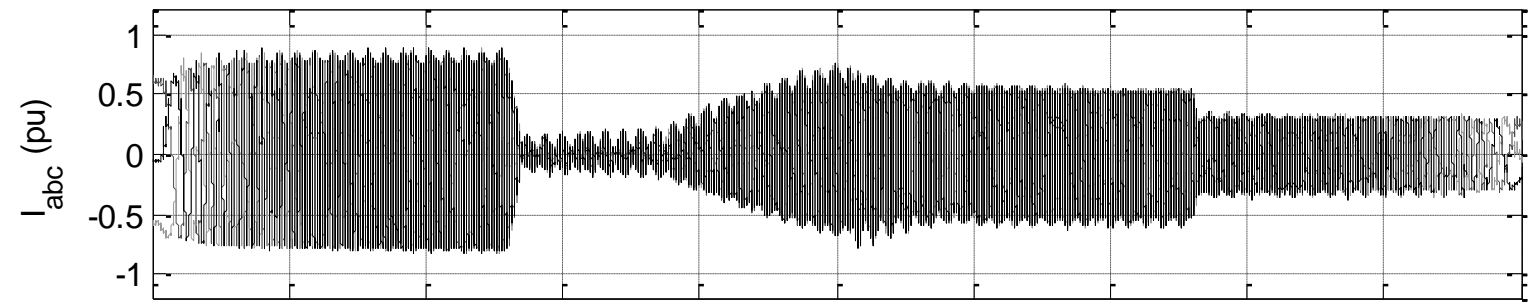

(a) Phase currents.

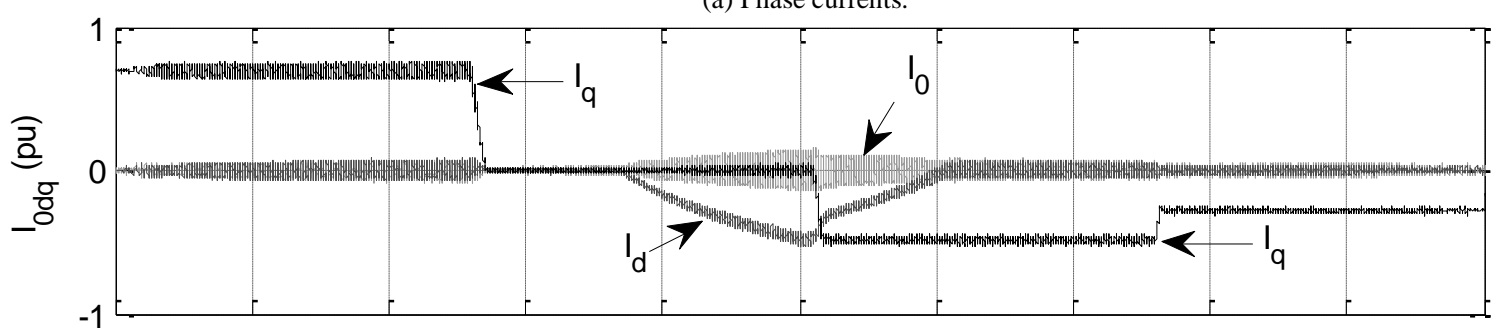

(b) Currents expressed in the synchronous reference frame.

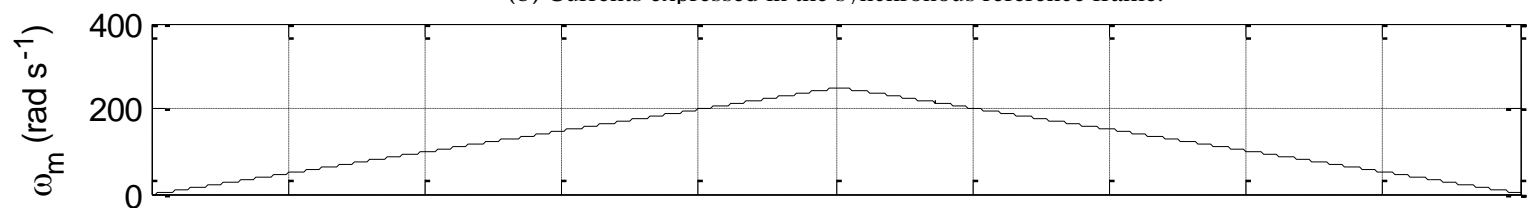

(c) Mechanical speed.

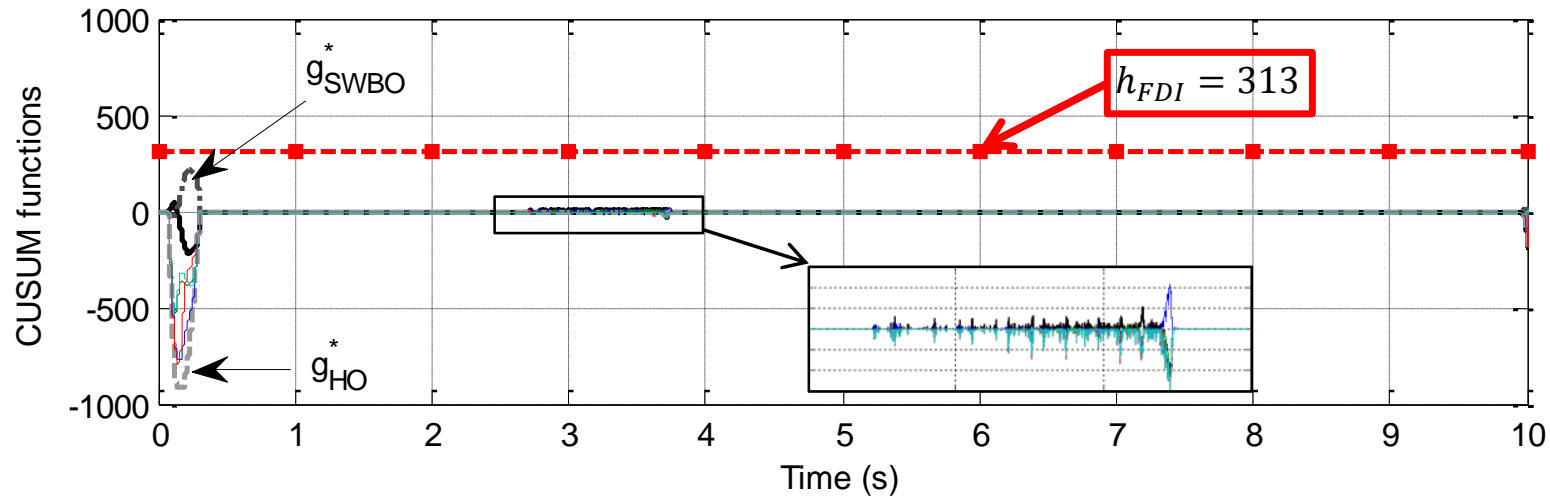

(d) CUSUM functions.

Fig. 16. Experimental results of the proposed FDI scheme under non-stationary and healthy conditions.

The second most likely state is SWBO as it was expected and the healthy state is again the less likely state.

Fig. 15(a) and (b) show simulations and experimental results respectively. It can be seen that the patterns are equivalent. It takes $0.25 \mathrm{~s}$ to cross the isolation threshold in simulations and experiments, what is in perfect concordance with the detection delay.

Fig. 14 and Fig. 15 validate the FDI method in steady state. The next section is dedicated to the performances under nonstationary conditions.

\section{EVALUATION UNDER NON-STATIONARY CONDITIONS}

So far, the FDI scheme has been designed according to simulation results obtained in steady state. To be embedded in electric vehicles, the method needs to be suitable for the operating conditions encountered in the field. That is, the method has to be robust against speed changes and load steps. The method should also be able to work at zero current, in the flux-weakening region and during energy recovery phases. If it is not possible to detect a fault, at least no false alarms may occur.

To verify that the proposed method is suitable, the following test has been conducted. At time $t=0 \mathrm{~s}$, the machine starts rotating and the speed increases from zero to a maximum speed equal to $250 \mathrm{rad} / \mathrm{s}$. The acceleration takes 5 seconds. When the maximum is crossed, the machine speed decreases to zero speed with a constant deceleration during 5 seconds (see Fig. 16(c), Fig. 18(c) and Fig. 19(c) for the speed profile).

Regarding the load profile, $I_{q}^{*}=0.7 \mathrm{pu}$ from $\mathrm{t}=0 \mathrm{~s}$ until $\mathrm{t}=2.5 \mathrm{~s} ; I_{q}^{*}=0 \mathrm{pu}$ from $\mathrm{t}=2.5 \mathrm{~s}$ until $\mathrm{t}=5 \mathrm{~s} ; I_{q}^{*}=-0.5 \mathrm{pu}$ from $\mathrm{t}=5 \mathrm{~s}$ until $\mathrm{t}=7.5 \mathrm{~s} ; \quad I_{q}^{*}=-0.3 \mathrm{pu}$ from $\mathrm{t}=7.5 \mathrm{~s}$ until $\mathrm{t}=10 \mathrm{~s}$. Around $\mathrm{t}=3.5 \mathrm{~s}$, the drive enters in the flux-weakening region until $t=6$ s (see Fig. 16(b), Fig. 18(b) and Fig. 19(b)).

For practical implementation, the speed profile is imposed by the load machine, while the torque profile is imposed by the machine under study.

Fig. 16 shows experimental results of the proposed FDI method in healthy operation. The three-phase currents are 
shown in Fig. 16(a), while the $0 d q$ currents are shown in Fig. 16(b). $I_{q}$ follows the torque profile, while $I_{d}$ is imposed by the controller to satisfy the voltage limit in the flux-weakening region. The zero-sequence current $I_{0}$ is nearly equal to zero during the test. The CUSUM functions are plotted in Fig. $16(d)$.

When the motor starts rotating, the CUSUM functions undergo a transient from $\mathrm{t}=0 \mathrm{~s}$ until $\mathrm{t}=0.23 \mathrm{~s}$, which is due to the synchronization time required by the QSG and the PLL. As shown in Fig. 17, the fault indices can take large values during this short period, but recover quickly when the speed increases. From $t=2.5 \mathrm{~s}$ until $\mathrm{t}=3.5 \mathrm{~s}$, the current references are equal to zero. Due to the low magnitude of the phase currents, the envelope-based indices take large values, as shown in Fig. 17(a) for $R_{M_{a b}}$. As there is no phase unbalance, each index takes successively large values but these values are not persistent. In this case, the CUSUM algorithm acts as a filter and the CUSUM functions are close to zero as highlighted in Fig. 16(d).

This test illustrates the behavior of the CUSUM algorithm, where additional intelligence allows avoiding false alarms due to non-stationary conditions or operation at low currents.

Fig. 18 shows experimental results of the proposed FDI method in case of single-switch open-circuit fault.

From $\mathrm{t}=0 \mathrm{~s}$ until $\mathrm{t}=2.5 \mathrm{~s}$, the speed increases and $I_{q}^{*}=0.7 \mathrm{pu}$. Because of the fault, the phase $a$ current has only negative values as shown in Fig. 18(a). Similarly, the zero-sequence current has only negative values within this period, while the $d$ - and $q$-axis currents are close to their references (Fig. 18(b)). Regarding the CUSUM functions of Fig. 18(d), it can be seen that the fault is not detected during the first moments. This is due to the dynamic of the filters which is low at low speed and to the synchronization of the PLL. Next, from $t=0.5 \mathrm{~s}$ until $\mathrm{t}=2.5 \mathrm{~s}$, the fault isolation is performed as expected, i.e. the CUSUM function $g_{S W A O}^{*}$ crosses the isolation threshold every $0.25 \mathrm{~s}$.

At $t=2.5 \mathrm{~s}$, the machine is operated at zero current. It can be seen that the fault is still isolated, even if the dynamics of the fault isolation is different. At $\mathrm{t}=5 \mathrm{~s}$, the energy recovery is activated while the machine is operated in the flux weakening region. For this particular operating condition, an uncontrolled positive current in the faulty phase can be observed in Fig. 18(a). This is a tricky case as the frequency indices $R_{\omega_{a}}$ is not much affected by the fault. Therefore it can be seen in Fig. 18(d) that the likelihood of the open-phase fault AO is almost equivalent. In any case, the FDI shows that the phase $a$ unbalance is well detected as the CUSUM functions of other faults keeps decreasing.

Finally, from time $t=6 \mathrm{~s}$ until $\mathrm{t}=10 \mathrm{~s}$, the machine is operated in the energy recovery mode and out of the flux-weakening region. The fault is isolated and the load steps at time $t=7.5 \mathrm{~s}$ has no effect on the FDI.

Fig. 19 shows experimental results of the proposed FDI method in case of open-phase fault (BO). The same test as for Fig. 18 is conducted. However, it can be seen that the fault is detected on the whole test and with a constant detection delay.

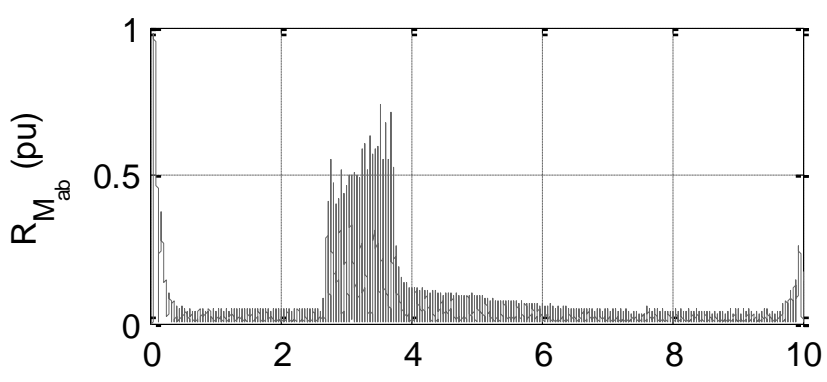

(a) Magnitude index $R_{M_{a b}}$.

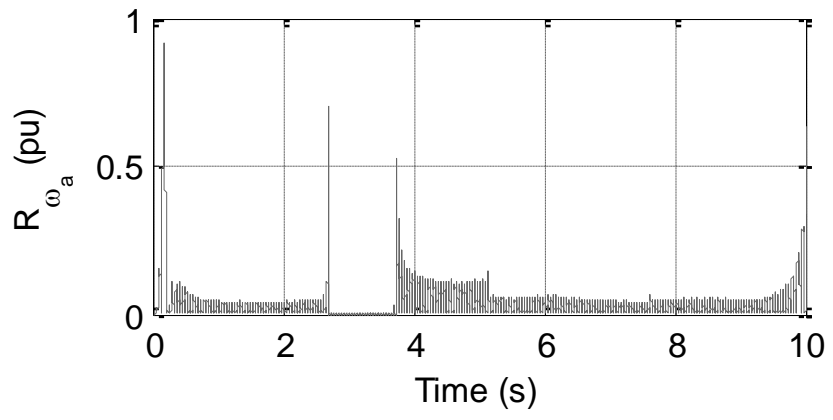

(b) Frequency index $R_{\omega_{a}}$.

Fig. 17. Fault indices obtained under non-stationary and healthy conditions.

\section{V.CONCLUSION}

Fault detection and isolation of inverter faults have been considered for a fault-tolerant topology. As the analysis of the current-vector trajectory is not suitable for this topology, other fault indices based on the knowledge of the fault characteristics have been derived. These indices are based on the unbalance of the phase currents as well as their instantaneous frequency.

To handle multiple indices and the isolation of multiple faults, the CUSUM algorithm has been introduced. This algorithm allows processing the fault indices by associating a likelihood ratio to each fault at each sample. By cumulating this likelihood ratio over several samples, it is possible to retrieve the most likely state of the drive with a high reliability.

This post-processing technique adds intelligence in diagnosis, which is required in some particular operating conditions to avoid false alarms.

The FDI method has been derived from simulation results in steady state with a validation by experiments at each step. To deal with EV environment, the robustness of the method has been tested in the following operating conditions: variable speed, load steps, at zero current, in the flux-weakening region and in energy recovery. The proposed FDI method performs well in all these modes. The simultaneous operation in the flux-weakening region and in energy recovery has been observed to be the most difficult condition for FDI of a singleswitch open-circuit fault, due to a large uncontrolled current in the faulty phase. 


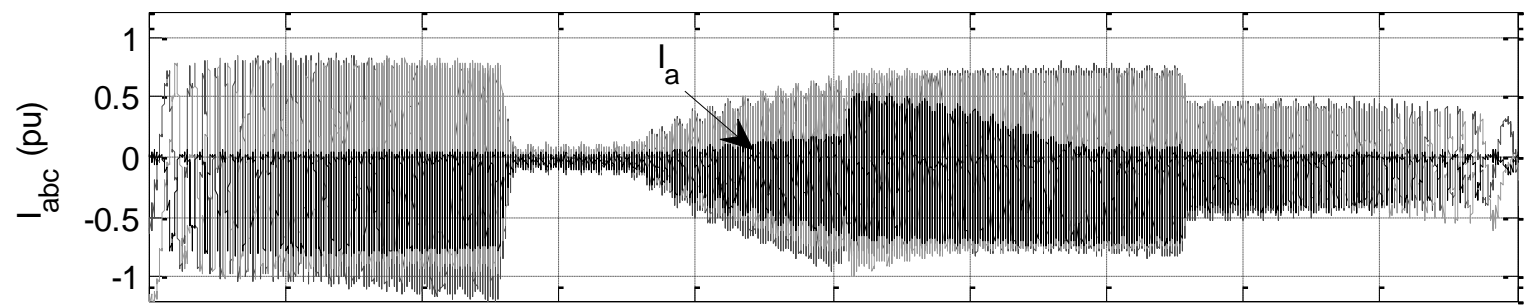

(a) Phase currents.

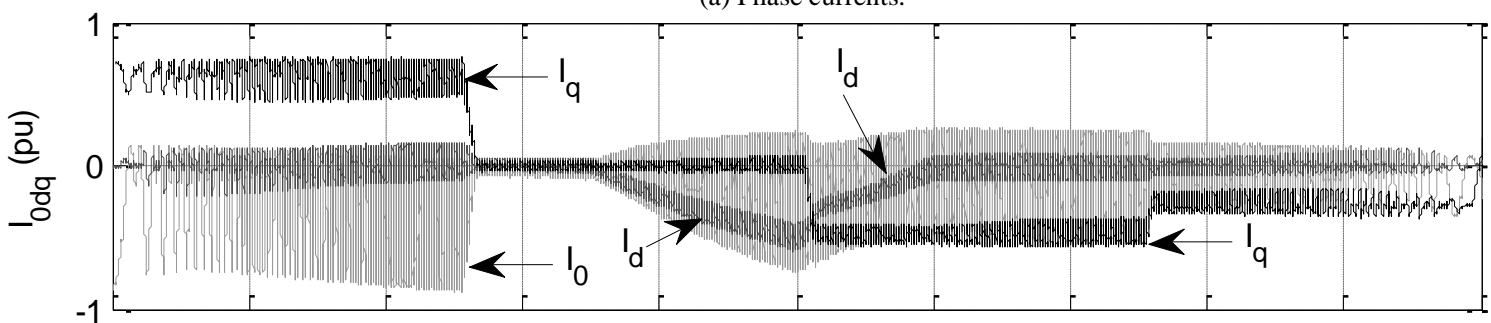

(b) Currents expressed in the synchronous reference frame.

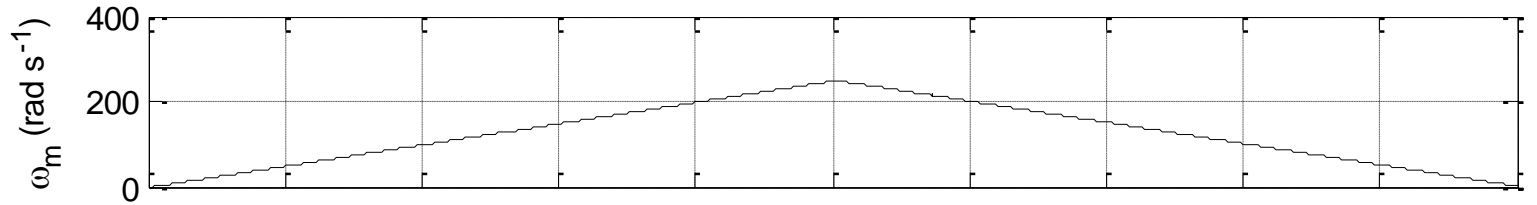

(c) Mechanical speed.

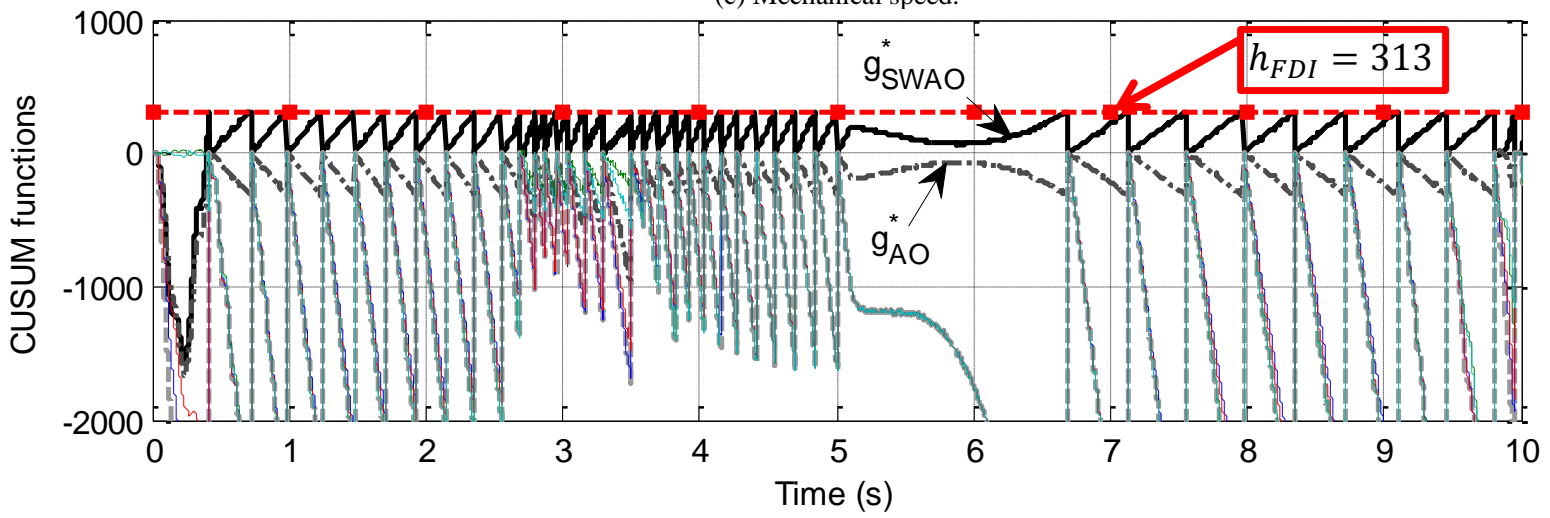

(d) CUSUM functions.

Fig. 18. Experimental results of the proposed FDI scheme under non-stationary conditions with a single-switch open-circuit fault (SWA1O).

This FDI scheme offers several possibilities for future research. First, the flexibility of the method allows the addition of other fault indices, which can be used for the isolation of other faults such as sensor and machine faults within the same decision system. An extension to inverter FDI in multi-phase drives can also be achieved easily.

Another possibility consists in implementing post-fault strategies dedicated for each faulty mode.

Regarding the application, future work will also be directed as regard to the efficiency of the solution and possible improvements such as soft-switching will be investigated on the converter side.

\section{REFERENCES}

[1] T. M. Jahns, "Improved Reliability in Solid-State AC Drives by Means of Multiple Independent Phase Drive Units," IEEE Transactions on Industry Applications, vol. 16, no. 3, pp. 321-331, May 1980

[2] S. Yang, A. Bryant, P. Mawby, D. Xiang, L. Ran and P. Tavner, "An industry-based survey of reliability in power electronic converters", IEEE Transactions on Industry Applications, vol. 47, no. 3, pp. 14411451, May-June 2011
[3] J.W. Bennett, G.J. Atkinson, B.C. Mecrow, and D.J. Atkinson, "FaultTolerant Design Considerations and Control Strategies for Aerospace Drives," IEEE Transactions on Industrial Electronics, vol.59, no.5, pp.2049-2058, May 2012

[4] A.L. Julian and G. Oriti, "A comparison of redundant inverter topologies to improve voltage source inverter reliability," IEEE Transactions on Industry Applications, vol. 43, no. 5, pp. 1371-1378, 2007

[5] M.E.H. Benbouzid and G.B. Kliman, "What stator current processingbased technique to use for induction motor rotor faults diagnosis?," IEEE Transactions on Energy Conversion, vol. 18, no. 2, pp. 238-244, Jun. 2003

[6] R.M. Tallam, T.G. Habetler, and R.G. Harley, "Stator winding turn-fault detection for closed-loop induction motor drives," IEEE Transactions on Industry Applications, vol.39, no.3, pp. 720- 724, May-June 2003

[7] Y. Gritli, A. Stefani, C. Rossi, F. Filippetti, and A. Chatti, "Experimental validation of doubly fed induction machine electrical faults diagnosis under time-varying conditions," Electric Power Systems Research, Volume 81, Issue 3, March 2011, Pages 751-766

[8] B. Akin, S.B. Ozturk, H.A. Toliyat, and M. Rayner, "DSP-Based Sensorless Electric Motor Fault Diagnosis Tools for Electric and Hybrid Electric Vehicle Powertrain Applications," IEEE Transactions on Vehicular Technology, vol.58, no.5, pp.2150-2159, Jun 2009 

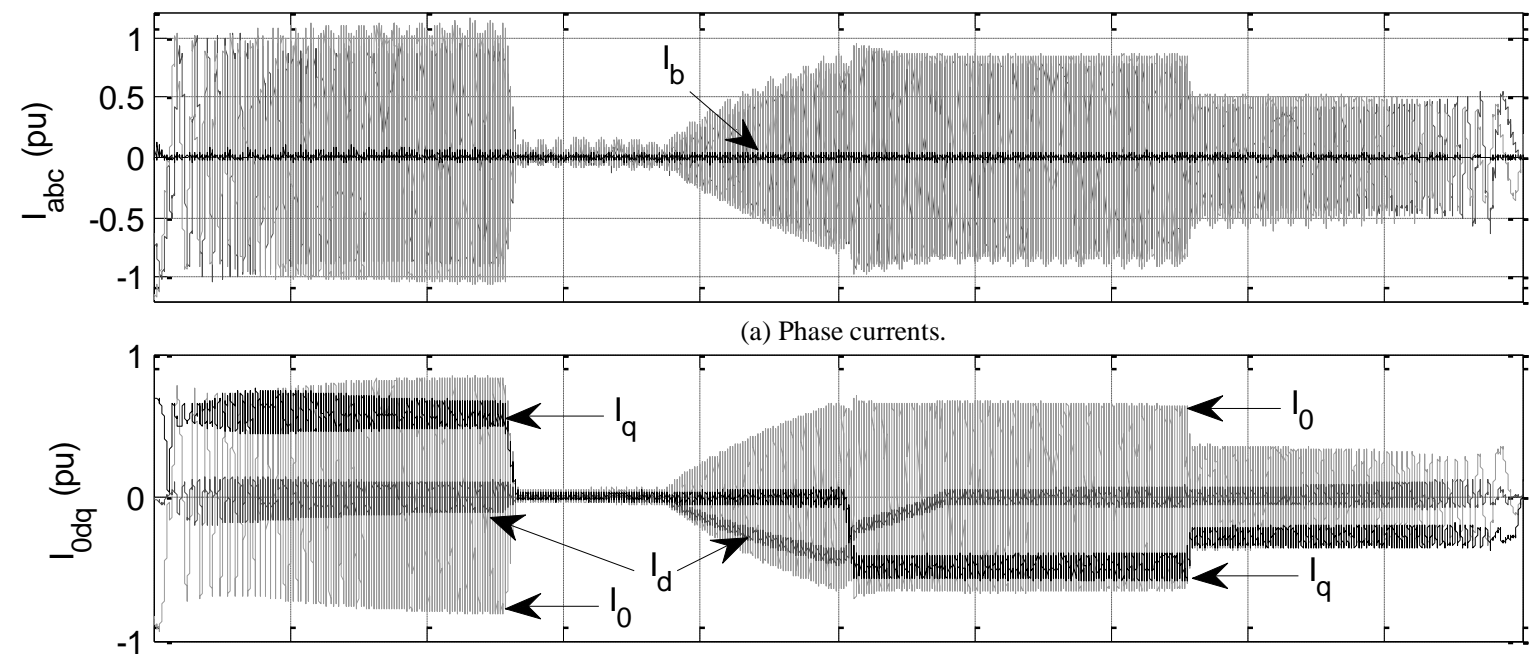

(b) Currents expressed in the synchronous reference frame.

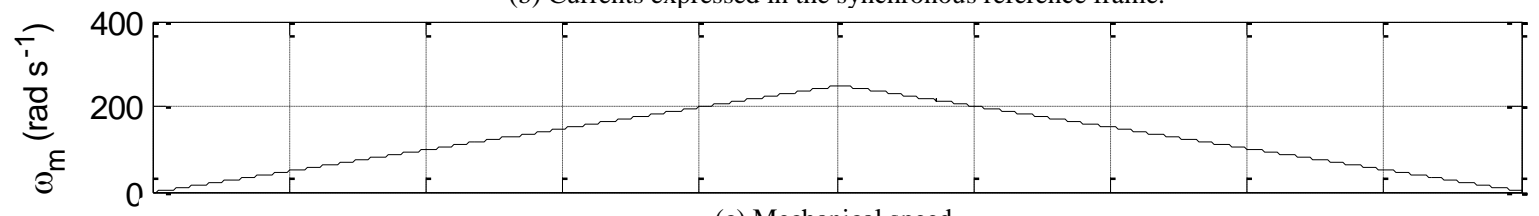

(c) Mechanical speed.

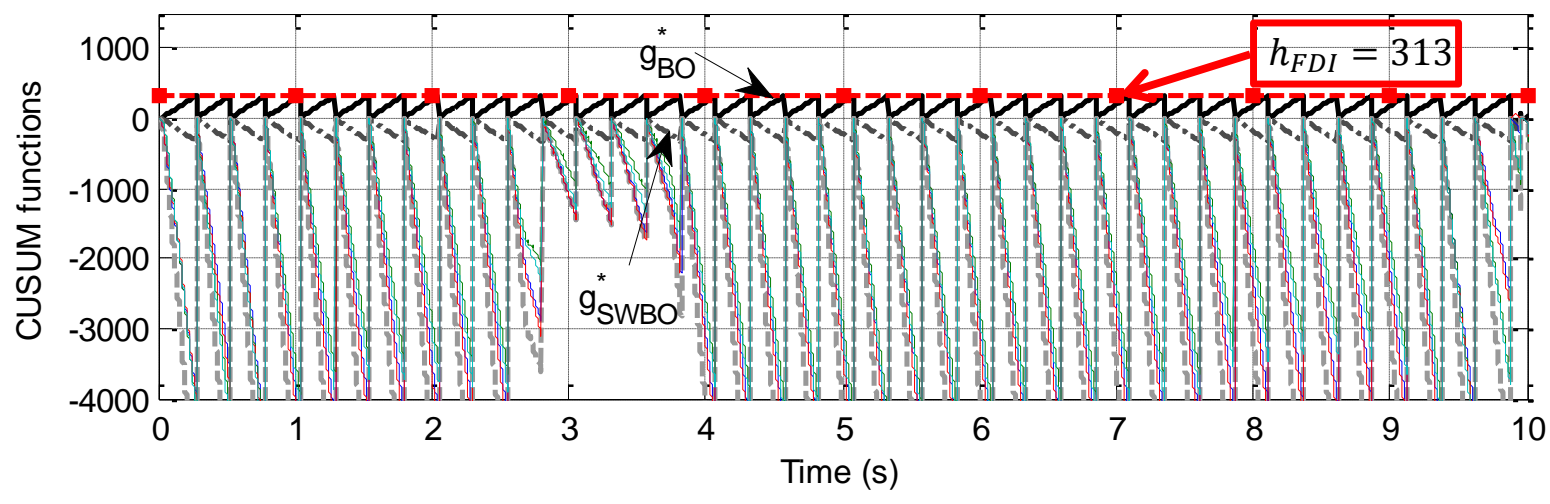

(d) CUSUM functions.

Fig. 19. Experimental results of the proposed FDI scheme under non-stationary conditions with an open-phase fault (BO).

[9] S. Yang, D. Xiang, A. Bryant, P. Mawby, L. Ran and P. Tavner, "Condition monitoring for device reliability in power electronic converters: a review", IEEE Transactions on Power Electronics, vol. 25, no. 11, pp. 2734-2752, November 2010

[10] N. Bianchi, M.D. Pre, and S. Bolognani, "Design of a fault-tolerant IPM motor for electric power steering," IEEE Transactions on Vehicular Technology, vol.55, no.4, pp.1102-1111, July 2006

[11] M. Barcaro, N. Bianchi, and F. Magnussen, "Faulty Operations of a PM Fractional Slot Machine with a Dual Three Phase Winding," IEEE Transactions on Industrial Electronics, vol. 58, no. 9, pp. 3825-3832, 2011

[12] L. Alberti, and N. Bianchi, "Experimental Tests of Dual Three-Phase Induction Motor Under Faulty Operating Condition," IEEE Transactions on Industrial Electronics, vol.59, no.5, pp.2041-2048, May 2012

[13] D. Fodorean, M. Ruba, D.C. Popa, and A. Miraoui, "Fault tolerant permanent magnet machines used in automobile applications," Electrical Machines (ICEM), 2010 XIX International Conference on, pp.1-6, 6-8 Sept. 2010

[14] B. A. Welchko, T. A. Lipo, T. M. Jahns, and S. E. Schulz, "Fault tolerant three-phase ac motor drive topologies; a comparison of features, cost, and limitations," IEEE Transactions on Power Electronics, vol. 19, no. 4, pp. 1108-1116, 2004

[15] E. Levi, "Multiphase Electric Machines for Variable-Speed Applications," IEEE Transactions on Industrial Electronics, vol. 55, no. 5, pp. 1893-1909, May 2008

[16] F. Locment, E. Semail, and X. Kestelyn, "Vectorial Approach-Based Control of a Seven-Phase Axial Flux Machine Designed for Fault
Operation," IEEE Transactions on Industrial Electronics, vol.55, no.10, pp.3682-3691, Oct. 2008

[17] J.W. Bennett, B.C. Mecrow, D.J. Atkinson, and G.J. Atkinson, "Safetycritical design of electromechanical actuation systems in commercial aircraft," IET Electric Power Applications, vol. 5, no. 1, p. 37, 2011

[18] L. de Lillo, L. Empringham, P. W. Wheeler, S. Khwan-On, C. Gerada, and M. N. Othman, "Multiphase Power Converter Drive for FaultTolerant Machine Development in Aerospace Applications," IEEE Transactions on Industrial Electronics, vol. 57, no. 2, pp. 575-583, Feb. 2010

[19] M. Naidu and S. Gopalakrishnan, "Fault-Tolerant Permanent Magnet Motor Drive Topologies for Automotive X-By-Wire Systems," IEEE Transactions on Industry Applications, vol. 46, no. 2, pp. 841-848, 2010

[20] P. Zheng, Y. Sui, J. Zhao, and C. Tong, "Investigation of a Novel FivePhase Modular Permanent-Magnet In-Wheel Motor," IEEE Transactions on Magnetics, vol. 47, no. 10, pp. 4084-4087, 2011

[21] R. Wang, and J. Wang, "Fault-Tolerant Control With Active Fault Diagnosis for Four-Wheel Independently Driven Electric Ground Vehicles," IEEE Transactions on Vehicular Technology, vol.60, no.9, pp.4276-4287, Nov. 2011

[22] L. De-Sousa, B. Bouchez, "Combined Electric Device for Powering and Charging", International Patent WO 2010/057892 A1

[23] L. De Sousa, B. Silvestre, B. Bouchez, "A combined multiphase electric drive and fast battery charger for Electric Vehicles", IEEE Vehicle Power and Propulsion Conference (VPPC), pp. 1-6, 1-3 Sept. 2010

[24] S. Haghbin, S. Lundmark, M. Alakula, and O. Carlson, "An Isolated High-Power Integrated Charger in Electrified-Vehicle Applications," 
IEEE Transactions on Vehicular Technology, vol.60, no.9, pp.41154126, Nov. 2011

[25] A. Akrad and M. Hilairet, "Design of a fault-tolerant controller based on observers for a PMSM drive," IEEE Transactions on Industrial Electronics, vol. 58, no. 4, pp. 1416-1427, 2011

[26] Y.-seok Jeong, S. K. Sul, S. E. Schulz, and N. R. Patel, "Fault detection and fault-tolerant control of interior permanent-magnet motor drive system for electric vehicle," IEEE Transactions on Industry Applications, vol. 41, no. 1, pp. 46-51, 2005

[27] K. Rothenhagen and F. W. Fuchs, "Current Sensor Fault Detection, Isolation, and Reconfiguration for Doubly Fed Induction Generators," IEEE Transactions on Industrial Electronics, vol. 56, no. 10, pp. 42394245, Oct. 2009

[28] M. Gálvez-Carrillo and M. Kinnaert, "Sensor fault detection and isolation in three-phase systems using a signal-based approach," Control Theory \& Applications, IET, vol. 4, no. 9, pp. 1838 - 1848, 2010

[29] F. Meinguet and J. Gyselinck, "Fault Detection, Isolation and Reconfiguration of Three-Phase AC Drive with Current Sensor Fault," in Electric Machines and Drives Conference, 2011. IEMDC'11. IEEE International, 2011, pp. 207-212

[30] D. Diallo, M. E. H. Benbouzid, and A. Makouf, "A Fault-Tolerant Control Architecture for Induction Motor Drives in Automotive Applications," IEEE Transactions on Vehicular Technology, vol. 53, no. 6, pp. 1847-1855, Nov. 2004

[31] R. Peuget, S. Courtine and J. P. Rognon, "Fault detection and isolation on a PWM inverter by knowledge-based model," IEEE Transactions on Industry Applications, vol. 34, no. 6, pp. 1318-1326, Nov./Dec. 1998

[32] M. A. Masrur, Z. Chen, B. Zhang, and L. Murphey, "Model-based fault diagnosis in electric drive inverters using artificial neural network," in Power Engineering Society General Meeting, 2007. IEEE, 2006, pp. 1-7

[33] F. Zidani, D. Diallo, M. E. H. Benbouzid, and R. Nait-Sait, "A fuzzybased approach for the diagnosis of fault modes in a voltage-fed PWM inverter induction motor drive," IEEE Transactions on Industrial Electronics, vol. 55, no. 2, pp. 586-593, 2008.

[34] W. Sleszynski, J. Nieznanski, and A. Cichowski, "Open-transistor fault diagnostics in voltage-source inverters by analyzing the load currents," IEEE Transactions on Industrial Electronics, vol. 56, no. 11, pp. 46814688,2009

[35] J.O. Estima, and A.J. Marques Cardoso, "A New Approach for RealTime Multiple Open-Circuit Fault Diagnosis in Voltage-Source Inverters", IEEE Transactions on Industry Applications, On page(s): 2487 - 2494 Volume: 47, Issue: 6, Nov.-Dec. 2011

[36] N. Freire, J. Estima, and A. J. Marques Cardoso, "Multiple open-circuit fault diagnosis in voltage-fed PWM motor drives using the current Park's Vector phase and the currents polarity," Diagnostics for Electric Machines, Power Electronics \& Drives (SDEMPED), 2011 IEEE International Symposium on, pp. 397-404, 2011

[37] D. U. Campos-Delgado and D. R. Espinoza-Trejo, "An Observer-Based Diagnosis Scheme for Single and Simultaneous Open-Switch Faults in Induction Motor Drives," IEEE Transactions on Industrial Electronics, vol. 58, no. 2, pp. 671-679, Feb. 2011

[38] L. Alberti, M. Barcaro, M.D. Pré, A. Faggion, L. Sgarbossa, N. Bianchi, and S. Bolognani, "IPM Machine Drive Design and Tests for an Integrated Starter-Alternator Application," IEEE Transactions on Industry Applications, vol.46, no.3, pp.993-1001, May-june 2010

[39] F. Meinguet, X. Kestelyn, E. Semail, and J. Gyselinck, "Fault Detection, Isolation and Control Reconfiguration of Three-Phase PMSM Drives," in the IEEE International Symposium on Industrial Electronics (ISIE), 2011, pp. 2091-2096

[40] S. Dwari and L. Parsa, "Fault-tolerant control of five-phase permanentmagnet motors with trapezoidal back EMF," IEEE Transactions on Industrial Electronics, vol. 58, no. 2, pp. 476-485, 2011

[41] X. Kestelyn and E. Semail, "A Vectorial Approach for Generation of Optimal Current References for Multiphase Permanent-Magnet Synchronous Machines in Real Time," IEEE Transactions on Industrial Electronics, vol. 58, no. 11, pp. 5057-5065, Nov. 2011

[42] A. Tani, M. Mengoni, L. Zarri, G. Serra, and D. Casadei , "Control of Multiphase Induction Motors With an Odd Number of Phases Under Open-Circuit Phase Faults," IEEE Transactions on Power Electronics, vol.27, no.2, pp.565-577, Feb. 2012

[43] P. Rodríguez, A. Luna, I. Candela, R. Mujal, R. Teodorescu, and F. Blaabjerg, "Multiresonant Frequency-Locked Loop for Grid Synchronization of Power Converters Under Distorted Grid Conditions," IEEE Transactions on Industrial Electronics, vol.58, no.1, pp.127-138, Jan. 2011
[44] S.K. Chung, "A phase tracking system for three phase utility interface inverters," IEEE Transactions on Power Electronics, vol. 15, no. 3, pp. $431-438,2000$

[45] M. Blanke, M. Kinnaert, J. Lunze, and M. Staroswiecki, "Fault-tolerant control of continuous-variable systems," in Diagnosis and fault-tolerant control, vol. 0, Springer, 2006, pp. 299-368

[46] V.-T. Phan and H.-H. Lee, "Performance Enhancement of Stand-Alone DFIG Systems With Control of Rotor and Load Side Converters Using Resonant Controllers," IEEE Transactions on Industry Applications, vol. 48, no. 1, pp. 199-210, Jan. 2012

[47] I.V. Nikiforov, "A simple recursive algorithm for diagnosis of abrupt changes in random signals," IEEE Transactions on Information Theory, vol.46, no.7, pp.2740-2746, Nov 2000

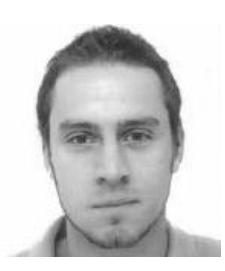

Fabien Meinguet (M'13) received the master degree in electrical engineering in 2007 from the Brussels School of Engineering, Université libre de Bruxelles, Belgium and the $\mathrm{PhD}$ degree in 2012 from the same institution. He is currently working as a post-doc at L2EP, in Arts et Métiers ParisTech, Lille, France. His main research interests are fault-tolerant drives, including design, control and diagnosis.

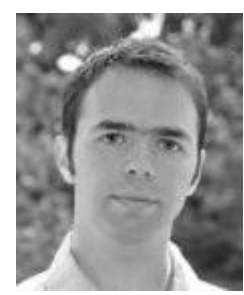

Paul Sandulescu (S`10) was born in Bucharest, Romania in 1986. He received the M.S. degree in electrical engineering in 2009 from Politehnica University of Bucharest, Romania. From 2009 he is a member of L2EP, Lille, France where he has been working in the System Control Team.

From 2010 he has been working toward the Ph.D. degree at Arts et Metiers Paristech, Lille in partnership with VALEO Powertrain Systems within the SOFRACI project. His research interests include multiphase machine drive systems modeling and control, and power electronics for automotive applications.

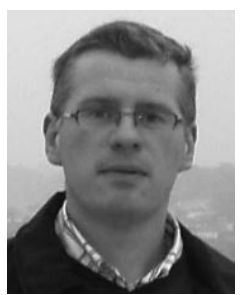

Xavier Kestelyn (M'08) was born in Dunkerque, France, in 1971. He received the Ph.D. degree in electrical engineering from Lille University, Lille, France, in 2003. After ten years as a teacher of electrical engineering in high school, he is currently an Associate Professor of electrical engineering with the Laboratory of Electrical Engineering and Power Electronics of Lille (L2EP), Centre d'Enseignement et de Recherche, Arts et Métiers ParisTech, Lille, France. His research interests include the modeling and control of multimachine systems such as multiphase machines and overactuated industrial robots.

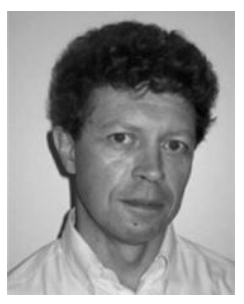

Eric Semail (M'02) received the M.S. degree from Ecole Normale Supérieure, Paris, France, in 1986 and the Ph.D. degree, with specializations in tools and studying method of polyphase electrical systems and generalization of the space vector theory, from Lille University, Lille, France, in 2000. He is currently with the Laboratory of Electrical Engineering and Power Electronics of Lille (L2EP), Centres d'Enseignement et de Recherche, Arts et Métiers ParisTech, Lille, where he became an Associate Professor in 2001 and a full Professor in 2010. In L2EP, his fields of interest include the design, modeling, and control of multiphase drives (converters and ac drives). More generally, he studies multimachine and multiconverter systems. His application fields are automotive, marine, and offshore wind power. 